\title{
THE DESIGN OF AN ADAPTIVE CONTENT MANAGEMENT LEARNING SYSTEM FOR CHILDREN WITH AUTISM
}

\author{
Khaled Ismail*, Nazean Jomhari \\ Faculty of Computer Science and Information Technology, University of Malaya, Malaysia \\ k.ismail@siswa.um.edu.my,nazean@um.edu.my
}

\begin{abstract}
The prevalence of autism in children in the world is estimated as one per 62 children, higher levels reported in some countries. These children experience significant problems with the development of social, behavioural and verbal and non-verbal communication skills. The skills impairment levels varies from an individual to another and that made teaching autistics a challenge for caregivers such as teachers and relatives. Hence, there are quite a number of frameworks of a software learning systems which focus on gaining the children's attention using representational visual illustration as a learning method instead of the textual form. However, majority of these tools are lacking the personalisation ability to suite everyone in the spectrum. Assistive technology offers an alternative way to attract children with autism. Therefore, this research is proposing an Adaptive Content Management Learning System (ACMLS) model to assist caregivers to produce, design and fine-tune or customise the learning materials appropriately so that the system interface and the materials are suitable for every individual in the spectrum according to each child personal profile aiming to make learning attractive and to contribute in improving their social, communication and behavioural skills and nonetheless, their attention level to the delivered educational topics. The ACMLS model design adopts four main components which are: (1) Design component: which covers the visual design, design principles and the mental model of the children
\end{abstract}


with autism. (2) Technology component: which covers the assistive technology tools and the architecture of the ACMLS system. (3) Education component: Which covers the learning objectives, styles, strategies, methods and the cognitive model. (4) Participants component: which covers the main participants who're playing a role in the ACMLS model such as: caregivers and children with autism.

Keywords: Children with autism, Education, Learning tools, Design, Intervention, Assistive Technology.

\section{Background}

The term 'Autism Spectrum Disorders' (ASD) refers to a cluster of developmental disorders that present from birth or very early in development, with usually life-long effects on essential human behaviours such as social interaction, communication, imagination, and relationships with others (National Research Council, 2001). ASD has been characterized as a spectrum of difficulties in these areas that vary in combination and severity, between and within individuals (Charman, 2002). ASD includes various conditions such as autistic disorder, Asperger syndrome, pervasive developmental disorder not otherwise specified (PDD-NOS) and Rett syndrome based on American Psychiatric Association reports (American Psychiatric Association, 1994) and international classification disease (ICD-10) and World Health Organization (1992). According to the DSM-IV-TR, autism is a severe disorder characterized by the presence of at least 6 out of 12 symptoms concerning communication, joint social interaction, behaviour, and activities that are present from the age of three years (American Psychiatric Association, 2000).

While it is controversial whether the popularity rates of ASD are actually growing (Baird et al., 2006; Charman, 2002) or, because of factors such as changes in diagnostic conditions and 
increasing awareness and recognition (Wing \& Potter, 2002), it appears to be growing, significant occurrence rates are reported by a number of studies. For example, the Australian Advisory Board on Autism Spectrum Disorders reported an estimated popularity rate for ASD across Australia, based on the Commonwealth government's Centreline data, of 62.5 per 10,000 for 6 to 12 -yearold children (K. Williams, MacDermott, Ridley, Glasson, \& Wray, 2008).

Similar popularity rates have been found in other studies; Charman (2002) reviewed three recent prevalence studies and suggested an average frequency rate of 60 per 10,000 for children under 10 years old. (Wing \& Potter, 2002) reviewed 39 studies conducted internationally and reported occurrence rates of 60 per 10,000 for autism and higher rates for the broader spectrum. A prevalence rate of 62.5 per 10,000 indicates there is an average of one child with ASD for every 160 children between 6 and 12 years (K. Williams et al., 2008).

Significantly, ASD is like other disabilities, has considerable social impact, especially on family and education. (K. Williams et al., 2008) point out that, with a popularity rate of 62.5 per 10,000 , ASD affects families containing half a million Australians. The families of individuals with ASD experience demands in a variety of family life contexts, including the needs of parents, both as individuals and as a couple (National Research Council, 2001), and of siblings.

Children with autism spend less time engaged in social and non-social activities compared to a typical developed children that resulting in reduced learning opportunities for them (Kishida \& Kemp, 2006; McWilliam \& Bailey Jr, 1995; Ruble \& McGrew, 2007). Promoting and supporting engagement is considered as an effective learning intervention for children with autism (Corsello, 2005; National Research Council, 2001), although certain behavioural, educational, and pharmacological interventions have been demonstrated to be helpful for many individuals with autism, there is currently no cure for the disorder (White, Keonig, \& Scahill, 2007). Learning and 
behavioural interventions methods widely used such as: Treatment and Education of Autistic and related Communication handicapped Children (TEACCH) method and Applied Behavioural Analysis (ABA) method, these methods will be explained in section 2.4. And according to Ruble and McGrew (2007) parents admitted that behavioural and educational mixed methods are an effective and productive method as an intervention technique. Additionally, an early intervention can provide long-term improvements to a child's ability to integrate with society (Matson \& Smith, 2008; Wetherby \& Woods, 2006).

Education is extremely important for children with autism, and research continues on developing educational goals appropriate for them with the aim of promoting personal independence and social responsibility (National Research Council, 2001). Educational interventions have been characterized by active engagement in intensive instructional programs accompanied by ongoing measurements of progress toward educational objectives (National Research Council, 2001).

Investigation of the subjective experiences of children with autism has the potential to make educational interventions more effective by treating them as independent entities. It allows for a more in-depth mediation between learners' inner world of personal experience and the public world of social knowledge within which they function (Pring, 2000).

\section{Traditional Interventional Methods and Approaches}

Traditional therapy techniques and tools for teaching children with autism about emotions are Social Stories ${ }^{\mathrm{TM}}$, Developmental Individualized and Relationship based (DIR) / Floortime, Social Communication Emotional Regulation, Transactional Support (SCERTS), Applied Behavioural Analysis (ABA), Early Intensive Behavioural Intervention (EIBI), Picture Exchange 
Communication System (PECS) and Treatment and Education of Autistic and Related Communication Handicapped CHildren (TEACCH).

Gray and Garand (1993) developed social stories which is an approach for teaching individuals with ASD social behaviours. They are short stories that describe and give information about social situations or interaction which children may find difficult or confusing. Their main goal is to provide accurate social information for improving understanding of events that may lead to more effective responses and not for effecting changes. DIR / Floortime parent intervention (Pajareya \& Nopmaneejumruslers, 2012) can help children with autism to connect emotionally and to build social and intellectual skills. This approach follows the child's emotional interests and provides one to one, intensive, play - based intervention. SCERTS is a framework that incorporates practices from other approaches and evidence-based practices (Prizant, Wetherby, Rubin, \& Laurent, 2003). It is a supporting multidisciplinary model for children with autism to enhance socio-emotional and communication abilities. The ABA therapy is often used as a treatment for children with autism. It is a widespread and recognized method for increasing learning, communication and appropriate social behaviour (Axelrod, McElrath, \& Wine, 2012). Positive reinforcement, reward for desired behaviours and ignorance for inappropriate behaviours are the main characteristics. According to the ABA intervention method, teaching children with autism about emotions can be achieved by providing examples of appropriate emotional behaviour and then rewarding when a child gives the correct emotional response. Young children with autisms usually receive a home-based program, the EIBI, which is based on the principles and technologies of ABA (Reichow, 2012). Early intervention appears to lessen the effects of autism and children with autism appear most able to benefit when intervention begins very early (2-4 years old) (Peters-Scheffer, Didden, Korzilius, \& Sturmey, 2011; Tzanakaki et al., 2012). Toddlers, who attended an early intervention program, 
appear to benefit from this, since $31 \%$ of those children were functioning in the typical developing range after the intervention (Stahmer, Akshoomoff, \& Cunningham, 2011).

Table 2.1: Traditional Interventional Approaches

\begin{tabular}{|c|c|c|}
\hline & $\begin{array}{l}\text { Applied Behavioural Analysis } \\
\text { (ABA) }\end{array}$ & $\begin{array}{l}\text { Treatment and Education of } \\
\text { Autistic and related } \\
\text { Communication Handicapped } \\
\text { CHildren (TEACCH) }\end{array}$ \\
\hline Type of Model & Behavioural Model & Educational/School Model \\
\hline $\begin{array}{c}\text { Typical } \\
\text { Teaching } \\
\text { Techniques }\end{array}$ & $\begin{array}{l}\text { Incidental Teaching } \\
\text { Discrete Trial Teaching }\end{array}$ & Structured Teaching \\
\hline $\begin{array}{l}\text { Typical } \\
\text { Therapy } \\
\text { Session }\end{array}$ & $\begin{array}{l}\text { Devoted to a task ( } 3-5 \text { minutes } \\
\text { Two or three hour's sessions. } \\
\text { Short periods of structured time). } \\
\text { Followed by an equal amount of } \\
\text { free play for the child ( } 3-5 \\
\text { minutes). } \\
\text { Longer break (10-15 minutes) at } \\
\text { the end of every hour. } \\
\text { Free play and breaks are used for } \\
\text { incidental teaching or practicing } \\
\text { learned skills in new } \\
\text { environment. }\end{array}$ & $\begin{array}{l}\text { Environments are created with } \\
\text { clear, concrete, visual information. } \\
\text { Visual schedules, routines, } \\
\text { organisational strategies (e.g., } \\
\text { working from left to right), and } \\
\text { visual work systems are used that } \\
\text { help a child achieve independence } \\
\text { in various skills. }\end{array}$ \\
\hline
\end{tabular}

Kaldy, Kraper, Carter, and Blaser (2011) and Gonzalez, Martin, Minshew, and Behrmann (2013) are reported that Children with autism have strong visual processing capability and a good performance on difficult visual search tasks. Augmentative and Alternative Communication (AAC), such as PECS, is frequently used to increase functional communication in children with autism. PECS is an effective visually-based system for communication via icons (Ganz, Simpson, \& Lund, 2012). Visual supports are also suggested for social skill development enhancement in young children with autism (Moody, 2012). Picture cards with cartoon faces or illustrations of people faces or photos showing different facial emotional expressions reinforce and support learning. Programs that emphasize visual support strategies are commonly used in education 
classrooms. A well-known and widely applied model, the TEACCH, is a teaching strategy which emphasizes in structured and predictable learning environment. It utilizes visual cues to increase independence and to teach new skills, such as facial emotions, to children with autism. It involves daily schedules, visual materials, individualized treatment and parental support (G. B. Mesibov, Shea, \& Schopler, 2005).

\subsection{Intervention Techniques and Treatment}

Autism is currently considered a behavioural syndrome. The diagnosis is based on the observation of a series of signs representing the expression of a functional impairment in three areas: social interaction; communication; interests and activities. It follows that the treatment includes the activation of actions to improve the social interaction and communication, as well as to encourage the broadening of interests and behaviour flexibility.

The majority of the studies on autism focused on epidemiology, genetics and neurobiology, but more intervention research is needed to help children with autism, their caregivers and educators. In this context, it is crucial to develop tools for neurocognitive intervention enabling children with autism to improve their ability to carry on everyday activities. The chances of success increase dramatically if the intervention is started at an early age.

Crucial factors are:

- Identify autistic children and intervene as soon as possible, as this may improve the speed of the child's general development, with a reduction of inappropriate behaviours, and better longterm functional outcomes;

- Tailor the interventions on the basis of the specific strengths and needs of the child and family;

- Constantly monitoring the child's progress. 
Parents must be actively involved, to the extent of their resources, in all aspects of the child's assessment and intervention.

Evidence (S. J. Rogers, 1998) shows that the most effective treatments are starting between 2 and 4 years of age. Also, the establishment of appropriate management strategies in the early years seems to minimize, or even avoid, many subsequent behavioural problems and to gain cognitive and adaptive functioning, with respect to children who do not receive services (Harris \& Handleman, 2000; Remington et al., 2007).

No a unique strategy of intervention is ever likely to be effective for all children and all families and it should be adapted to individual needs (Howlin, 1998). Nonetheless, the strategies commonly recommended and adopted, may be categorized into behavioural and evolutionary approaches.

The following section briefly discusses the main models of intervention and then Treatment and Education of Autistic and Communication Handicap Children normal development (TEACCH) approach as one base type of intervention for children with autism will be described.

\subsubsection{Behavioural and Evolutionary Approaches}

Applied Behaviour Analysis (ABA) consists in the study of behaviour, behaviour changes and the factors that determine these changes based on the following 4 elements:

1. The antecedents preceding the observed behaviour;

2. The observable and measurable actual behaviour;

3. The consequences deriving from the observed specific conduct; 
4. The context (i.e. place, people, materials, activities or time of day) in which the behaviour occurs.

The techniques used by behaviour therapy to promote changes in the person's conduct typically are: the prompting, the modelling, the shaping and the reinforcement. ABA has been used since 1960 to teach specific skills to improve socialization, communication and adaptive behaviour. In the early 80's Lovaas developed the Discrete Trial Training (Ole Ivar Lovaas et al., 1981), a treatment protocol including a series of sessions, for a total of 40 hours weekly. The theoretical assumption is that the whole behaviour can be resolved into its cause (antecedent) and consequence which can be controlled through a careful analysis of the behaviour and training. The positive reinforcement is a key point of the method to change and shape the behaviour. According to Lovaas et al., the task will continue if positively reinforced, while it will stop when ignored or punished. This model has two basic assumption:

- The need for a highly structured teaching, with a 1:1 ratio, in an environment specifically organised;

- The inability of the autistic child to learn in a "natural" environment that often acts only as a "distraction".

On these assumptions the model "The University of California at Los Angeles (UCLA) Young Autism Project" has been developing. Designed by Lovaas (O Ivar Lovaas, 1979; Ole Ivar Lovaas et al., 1981) and based on Applied Behaviour Analysis (ABA), the model requires a large involvement of the children's families and a variable amount of hours per week (up to 40 hours per week). 
However, learning in an artificial environment may lead to problems of generalisation of the acquired skills. Also, it was recently recognized that ASDs children with autism can learn in "natural" environments, such as family or school, with the involvement of parents, brothers, teachers and peers, if they receive an appropriate training to implement the programs on the child.

On these grounds, several models was developed:

- "Walden Early Childhood programs at the Emery University School of Medicine", using incidental teaching (incidental Learning) in integrated classes (children with autism and normal children);

- "Learning Experiences, an Alternative Program for Preschoolers (LEAP) at the University of Colourado - School of Education," which is based on teaching to peers how to provide the treatment to the children with autism (National Research Council, 2001).

Further models are based on evolutionary approaches: e.g. "Denver Model at the University of Colourado" (S. Rogers, Hall, Osaki, Reaven, \& Herbison, 2000); "Developmental Intervention Model Health Sciences Centre at The George Washington University School of Medicine" (Greenspan \& Wieder, 1999); "Thérapie d'Echange et de Développement (TED) de l'Université François Rabelais, CHU de Tours" (Barthélémy, Hameury, \& Lelord, 1995), and are characterized by a "child-centred" intervention to promote free expression, initiative and participation. Emotional and relational dimensions are key points of this approach, as the environment is no more considered a mere physical space in which doing exercises, but a space in which the relation between the child and the operators is central. 


\subsubsection{TEACCH Approach}

Treatment and Education of Autistic and Communication Handicap Children normal development $(\mathrm{TEACCH})$ is a psycho-educational habilitation approach, based on a close collaboration between parents and professionals and on the integration of all interventions attended by the affected persons. It was created in the 60s by Eric Schopler (Cox \& Schopler, 1993) and aim to modify the environment to meet the needs of people with Autistic Disorder (E Schopler, 1994). Key features include: an early assessments and continuous monitoring after the first diagnosis, promoting active collaboration with other family members, teaching new adaptive skills, planning of specific interventions, using of cognitive-behavioural strategies. The TEACCH approach is addressed to act on those aspects which represent the major difficulties for autistic children, as the comprehension of abstract concepts, the meaning of imitation, the interpersonal relationships and the characteristics of events in space and in time. It was defined by Eric Schopler as a global approach based on a close collaboration between parents and professionals. The approach was specifically designed for children with autism and the parents are given the role of co-therapists. The purpose of TEACCH is to minimize the child's difficulties using structured and continuous intervention, environmental adaptation (modify the environment in order to meet the needs of autistic children) and augmentative communication.

The TEACCH approach is called "Structured Teaching" because it is based on the "Culture of autism" (G. B. Mesibov \& Shea, 2010) that highlights deficits and strengths of individuals with autism such as:

- Preference for visual information

- Attention to details but difficulties with sequencing, integrating tasks

- Variability in attention and difficulties shifting attention 
- Communication problems

- Problems with the time (for example in recognizing the beginning and the end of an activity

- Difficulties to generalise from the original learning situation

- Interest in favourite activities but also difficulties disengaging once engaged.

The principles of TEACCH's structured teaching include:

(a) Understanding the culture of autism;

(b) Developing a tailored person and family centred plan, rather than using a standard curriculum;

(c) Structuring the physical environment so that it will facilitate the understanding in the autistic students;

(d) Using visual supports to plan the sequence of the everyday activities, so to make them predictable and understandable;

(e) Using visual supports to make individual tasks understandable.

The foundation for structured teaching approach is the principle of modifying the environment to accommodate the needs of autistic students (Eric Schopler, Mesibov, \& Hearsey, 1995), which involves four connected components:

1. Physical organisation: The physical layout of the classroom or the area for teaching should help to adequately promote a student's independent functioning together with his recognition of and compliance with rules and limits. Visual information is provided as important element to direct the student's activities in a predictable manner.

2. Scheduling. Due to autistic student's problems with sequential memory and organisation of time, they need schedules. Visual schedules provide a clear timing of the activities that will 
take place and of their sequence (Eric Schopler et al., 1995). Schedules also assist them in predicting events, lessening their anxiety.

3. Work systems. Work systems visually specify to the students which activity should be completed in specific independent areas, the amount of work that must be done and when that work session or task is complete (Eric Schopler et al., 1995).

4. Task organisation. Task organisation determines which work students do independently, which needs to be done within a task, how many items must be completed, and expected outcomes (Eric Schopler et al., 1995).

As mentioned earlier that children with autism show a range of difficulties concerning organisation, attention, sequencing and generalisation that can vary in number and severity from one individual to another. This makes important to use targeted interventions, designed on the strengths and needs of each affected children (Eric Schopler \& Reichler, 1971) as, for instance, the TEACCH approach.

According to (Eric Schopler \& Reichler, 1971), children with autism responded more favourably to structure than unstructured settings. TEACCH approach demonstrated to be effective in improving the individual skills displayed during work sessions (Panerai, Ferrante, \& Caputo, 1997; Panerai, Ferrante, Caputo, \& Impellizzeri, 1998; Panerai, Ferrante, \& Zingale, 2002) and in reducing self-injurious behaviours (Norgate, 1998). Furthermore other studies found that TAECCH approach was effective to ameliorate developmental abilities in children with autism even when started at different ages: 4.06 ( \pm 0.529 ; range: $3-5)$ years (Tsang, Shek, Lam, Tang, \& Cheung, 2007) , 9.09 ( \pm 2.07 ; range: 6-14) years (Panerai et al., 2009), $4.42( \pm 1.025$; range: 3.6-5, 8) years (Ozonoff \& Cathcart, 1998); mean ages are reported. 


\subsubsection{Picture Exchange Communication System}

The Picture Exchange Communication System (PECS) is a visual communication system designed to increase a child's use of spontaneous and functional communication in their child's everyday environment (Ostryn, Wolfe, \& Rusch, 2008). The child uses PECS to exchange pictures of items to obtain desired objects and otherwise get his or her needs met. PECS does not necessarily aim to increase vocalization, but to help children improve their ability to spontaneously communicate in a functional manner during their day-today lives (Ostryn et al., 2008). PECS is delivered in six sequential phases, beginning with teaching requests, or "demands," and progresses to more sophisticated skills such as answering questions (Bondy \& Frost, 2002). Seven studies using PECS were reviewed by the Committee; four were strong analyses with positive outcomes, including one RCT (Yoder \& Stone, 2006). One interesting study compared PECS to sign language but had mixed results (Tincani, 2004), thus limiting the ability to draw direct comparisons. Although PECS has established evidence according to the Committee's rating rubric, it is surprising there are not more published studies of the intervention given its popularity in the field. More research is needed to compare the effectiveness of PECS with other aided and unaided communication systems.

Next section will present the assistive technology interventions tools used assist children with autism in enhancing impairments in social, behavioural and communication skills

\section{Assistive Technology Interventions}

Assistive technology (AT) educative methods are increasingly regarded as playing a key role in the education of children with autism (Konstantinidis, Luneski, Frantzidis, Costas, \& Bamidis, 2009). It includes any device, equipment or piece that enhances new skills, improves existing behaviours, or reduces the negative consequences of disabilities on daily functioning (Matson \& Boisjoli, 2008; Matson \& Goldin, 2013). Educational technology can be used either as a constant 
assistive tool or used temporarily as a teaching aid (Goldsmith \& LeBlanc, 2004). The use of technology in educational interventions for children with autism, such as computer-aided learning, has been shown to benefit areas such as literacy skills (Tjus, Heimann, \& Nelson, 2001; C. Williams, Wright, Callaghan, \& Coughlan, 2002), facial recognition abilities (Tanaka et al., 2010), and social skills (Mitchell, Parsons, \& Leonard, 2007; Piper, O'Brien, Morris, \& Winograd, 2006). Pennington (2010) also suggests that computer-aided instruction could be beneficial in other academic areas such as mathematics and science. Children with autism frequently need one-to-one adult instruction, but even when this is available there can still be issues with learning due to "noncompliance, lack of motivation, behavioural difficulties and engagement in stereotypical or ritualistic behaviours" (C. Williams et al., 2002). Technology offers an alternative provision of one-to-one instruction, but also the potential to overcome some of these additional issues.

AT serves to improve the students' quality of life in a manner appropriate to their individual differences and needs can be used to support persons with special educational needs in many areas of learning. Moreover, previous research has shown that children with autism often exhibit a strong interest and enjoyment interacting with technology as well as a high level of ability in using it (Goodwin, 2008; Higgins \& Boone, 1996; Putnam \& Chong, 2008).

Researchers have cited number of benefits that technology specifically offers children with autism, according to Bölte, Golan, Goodwin, and Zwaigenbaum (2010) the level of the child's social skills does not affect the interaction with the technology as it does with the class teacher and is particularly suitable for certain "domain-specific" learning (C. Williams et al., 2002).

Technology can be used to teach and reinforce specific skills in which children with autism can exhibit difficulties. It could be possible to use technology for a whole range of skills but previous research has mainly concentrated on communication and social skills (Grynszpan, Martin, \& 
Nadel, 2008; Parsons et al., 2000; Rajendran \& Mitchell, 2000), which are the skills children with autism typically struggle with, and has been shown to have a positive effect on learning. The same software can be used at both school and home, allowing the child to practice any areas they are struggling with outside of school in a learning environment they are used to and helping to provide training in generalisation (Panyan, 1984).

Moreover, a computer screen offers a smaller area of focus than a classroom setting, which means the child is less affected by the external environment and increases concentration on the task (C. Williams et al., 2002).

In the same way, technology offers a safe environment in which the child can make errors and learn from them without any fear of the consequences, giving the child more confidence to try unfamiliar things (Goldsmith \& LeBlanc, 2004; Konstantinidis et al., 2009).

Additionally, the material can be delivered in a visual way, which is a preferred way of learning for many children with autism (C. Williams et al., 2002). The software can be designed to provide as much additional one-to-one individualized support as required, the level of which can be varied between children adapting to their specific learning and other needs e.g. visual/hearing sensitivities (Goodwin, 2008; Higgins \& Boone, 1996; C. Williams et al., 2002). This can potentially reduce the amount of one-to-one teaching time the child requires (Panyan, 1984).

Nonetheless, technology can give the child more control over their learning, allowing them to work at their own pace and also are often appealing to children with autism, potentially increasing their engagement in the task (Bölte et al., 2010; Konstantinidis et al., 2009). Children with autism do not like change and technology can provide consistency across tasks, as well as being predictable and familiar (Bölte et al., 2010; Panyan, 1984; C. Williams et al., 2002). 
On the other hand, learning through technology has been shown to increase motivation and improve behaviour in children with autism (Goldsmith \& LeBlanc, 2004; Konstantinidis et al., 2009; C. Williams et al., 2002).

Although the use of technology in the education of children with autism can be beneficial, it is also important to keep in mind the potential issues that the use of technology could present, which include reducing the interaction time in class and replacing it with interaction with the technology could further isolate children with autism, reducing their opportunities for social interaction with the teacher and other children (Higgins \& Boone, 1996).

Children with autism often have obsessive-compulsive behaviours and the technology could become a focus of one of these, particularly if their special interest is related to technology in some way (C. Williams et al., 2002). It can be hard to tailor technology for each individual child effectively and adapt to their changing needs. When designing technology for this specific group it is difficult to generalise, as what works for one child may not always work for another due the vast differences between children on the autistic spectrum.

Children with autism find it hard to transfer skills they have learnt in one environment into another, and they might struggle applying skills they have learnt through interaction with the technology into a real world scenario. Therefore, not all skills are best taught using technology, it should be used to teach or reinforce appropriate skills and not seen as the answer to all problems experienced in the classroom-learning environment.

Overall the use of technology in educational interventions offers great potential for this population, and despite the concerns of some researchers there is mounting evidence that computers can provide a wide range of benefits to children with autism. It is however important that this technology is employed in appropriate situations and used to complement other successful 
teaching methods, to ensure the children still have exposure to social learning situations. This technology also needs to be appropriately designed ideally taking into account current theories of autism and structured approaches to learning as well as input from the ASD child population as the system informant which is the source of information, ideas and materials.

It is imperative for technology designers to be aware of the vast individual differences within autistics and the difficulty in achieving a universal technological solution to educating these individuals.

\subsection{AT for Social Skills}

As mentioned earlier and according to the diagnostic criteria of American Psychiatric Association (2013), ASD include deficit in social skills (e.g. lack of eye contact, poor peer's relationships, low joint attention, failure in social and emotional reciprocity). Studies by (Devine, 2014; Gelbar, Smith, \& Reichow, 2014) suggested that social deficits and emotional difficulties might cause isolation and social anxiety, which are dominant among ASD individuals.

Accordingly with the above, AT-based interventions are aimed at improving social skills and relationships within the ASD population (Van der Meer et al., 2015). Studies show that assistive technologies can be used to support those social skills which persons with autism disorder have difficulty in performing in daily life (Lang et al., 2014). Stasolla, Boccasini, Perilli, Damiani, and Albano (2015) reviewed ten AT studies were implemented to target different social skills such as: facial recognition, social verbalization, eye contacts and collaboration with peers. These studies showed improvement of the targeted skill. In addition, results emphasized that all participants significantly increased their performance during intervention compared to baselines phases. Moreover, for all of them the use of the technology seemed to be purposeful. 
Generally, different assistive technologies, such as toys, computer games, or sports equipment, adapted to the needs of students with special educational needs, enable them to make use of their leisure time and to participate in social activities (M. J. Reed et al., 2009; P. Reed \& Lahm, 2004; P. R. Reed \& Lahm, 2007).

\subsection{AT for Communication Purposes}

As mentioned earlier, children with autism exhibit a large range of communication impairments (G. E. Lancioni et al., 2010; G. E. Lancioni et al., 2009). For example, they may have a repetitive words and phrases, avoid gaze, disoriented. These symptoms may interfere with their daily life activities (G. E. Lancioni et al., 2007; Pinder-Amaker, 2014). Furthermore, communication impairments may interfere with their educational attainment which has its implication consequences for their quality of life (Lee \& Carter, 2012).

Based on the above symptoms, AT programs were implemented to improve the communication skills in order to cope with the outside world (Brown et al., 2011) and (Watkins \& Sparling, 2014). Since the technology solutions may influence the person's success significantly, it should be always personalized to ensure the person is able to communicate with the outside world (G. Lancioni, Singh, O'reilly, Oliva, \& Basili, 2005; Matson \& Jang, 2014).

In addition, AT helped to facilitate communication for students with special educational needs in different situations and environments (Cumley, Maro, \& Stanek, 2009). The methods used to help students who have difficulty in speaking communicate with their environment are called Augmentative/Alternative Communication (AAC). These methods include aided and/or unaided symbols. Assistive technologies provide the students who cannot effectively use speech with 
various opportunities such as the use of simple communication boards or high technology electronic systems (Cumley et al., 2009).

Generally, a number of technologies, including communication boards/books with pictures, eye gaze boards/frames, speech generating devices, text-based devices with speech synthesis and PECS can be used to support persons with communication problems and speech disorders (Coleman, 2011; McCulloch, 2004; M. J. Reed et al., 2009; P. Reed \& Lahm, 2004; P. R. Reed \& Bowser, 2013; P. R. Reed \& Lahm, 2007).

Rodríguez, Saz, Lleida, Vaquero, and Escartín (2008) reported that communication technologies provided persons with speech disorders the ability to communicate with others. Coleman, MacLauchlan, Cihak, Martin, and Wolbers (2015) found that the strategy of using PowerPoint presentations to teach vocabulary had a positive effect on improving the vocabulary of third-grade hearing impaired students in secondary school. Furthermore, in a study by Ferreira, Travassos, Sampaio, and Pereira-Guizzo (2013) which analysed the impact that the assistive technology of computer games had on children with Cerebral Palsy who were unable to speak, the results revealed that the children used the communication forms of sound or facial expressions, suggesting that assistive technologies are important for social interaction.

\subsection{AT for Adaptive and Daily Skills}

A third relevant issue is adaptive and daily activities. Children with autism may have difficulty in daily-life functions, such as eating, cooking, dressing and shopping. Technologies such as adapted toys or sports equipment can support persons with special educational needs in their daily lives (Bryant, Seok, Ok, \& Bryant, 2012; Gierach, 2009; P. R. Reed \& Lahm, 2007). For example, the assistive technologies such as 1) Simplified cookbooks such as 4 ingredient cookbook 2) Modified 
cookbooks (picture supported) 3) Visual or verbal directions for using heating equipment such as stove, oven, and microware 5) Visual directions to insure safety (what to do in case of spills or fire, 911 directions) and 6) Adapted timers (visual, talking, large display) can be used to support the skills required for cooking in daily life (Gierach, 2009).

Regarding to support daily life skills; Bouck, Meyer, Joshi, and Schleppenbach (2013) showed that two mentally-disabled students benefited from the use of audio records when creating a shopping list. Hersh and Johnson (2008) highlighted the effectiveness that tools such as adapted needles for sewing or distance measuring devices had in accommodating the daily life needs of the visually-impaired. Douglas, Wojcik, and Thompson (2012) revealed that Apple's smart phones and computers feature 280 applications that aim to support persons with mental and developmental disorders in their daily lives and suggested that the effect of these applications on learning should be investigated.

Generally, Stasolla et al. (2015) reviewed many studies which pointed out the AT increased the children constructive engagement and reduced stereotypic behaviours during intervention phases. Thus, AT is a helpful tool in enhance and improve their skills and construct the essential skills for the independent functioning within daily settings such as: at home and school (Zwaigenbaum et al., 2005).

Next section will introduce the design approaches and methods which in a way will guide the researcher to appropriately design and develop an adaptive content management learning system for children with autism to fulfil objective 3 from the research objectives in section 1.6. 


\section{ACMLS Model Components}

The proposed Adaptive Contents Management Learning System (ACMLS) model consists of four main components as illustrated in Figure 1 which are: Participants, Technology, Design and Education/learning. These components will be explained and discussed in details in the following sections. 


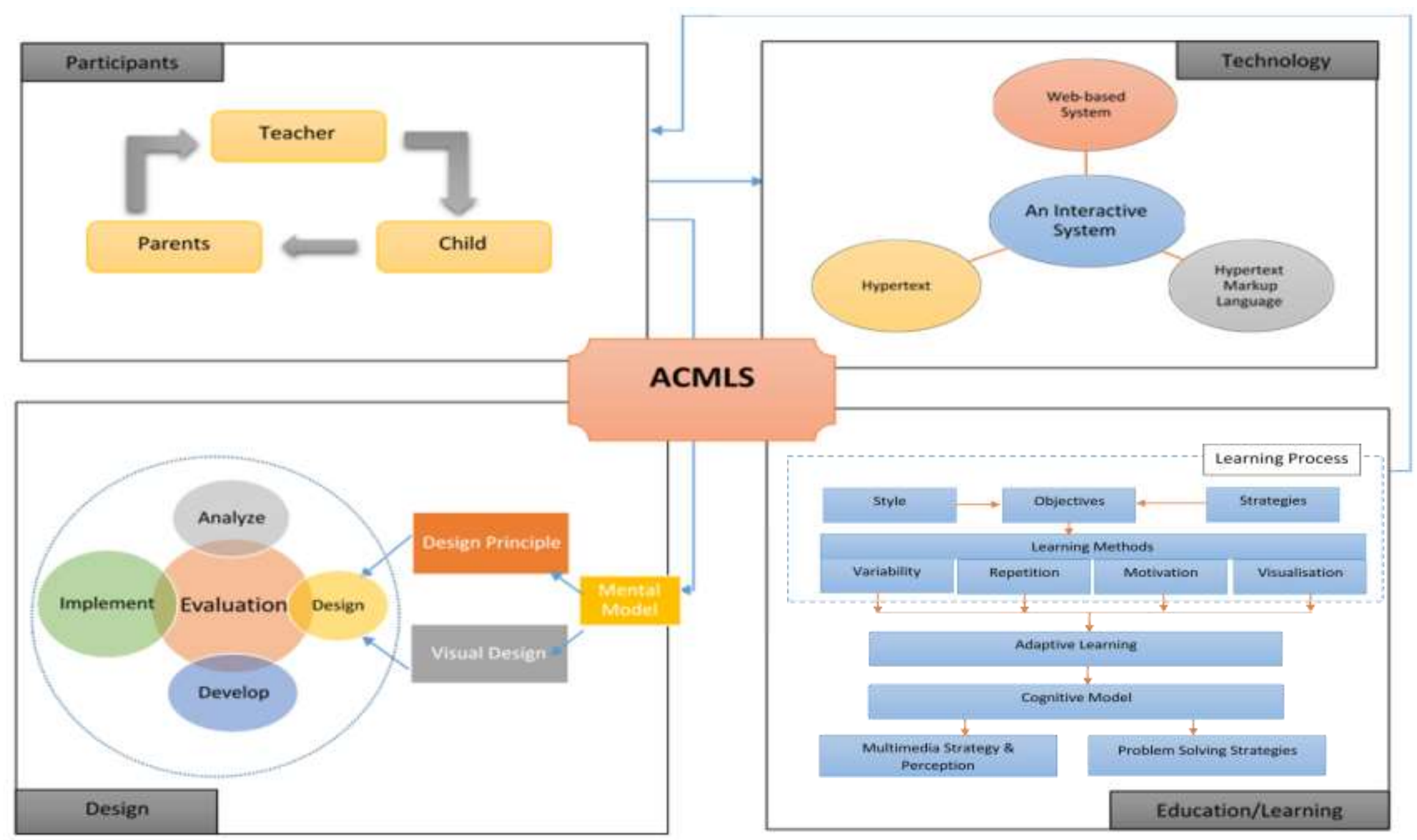

Figure 41: ACMLS Model 


\subsection{Participants Component}

$\underline{\text { Participants }}$ The concept of participant in this chapter has been particularly concerned with the developmental progress of the individuals with autism in their lifelong venture, which is learning for intrinsic reasons. As well as helping the teacher in school and the parents at home to focus on implementing the educational materials based on the curriculum and their daily life routine.

This component consists of the factors that can assist the teachers and parents at home and most importantly influence the children with autism particularly the development fulfilment concern at all stages in their lifelong. More so, the literature review, interviews and observations during the preliminary study helped the researcher to identify the methods and strategies which support gaining the attention during the learning activities.

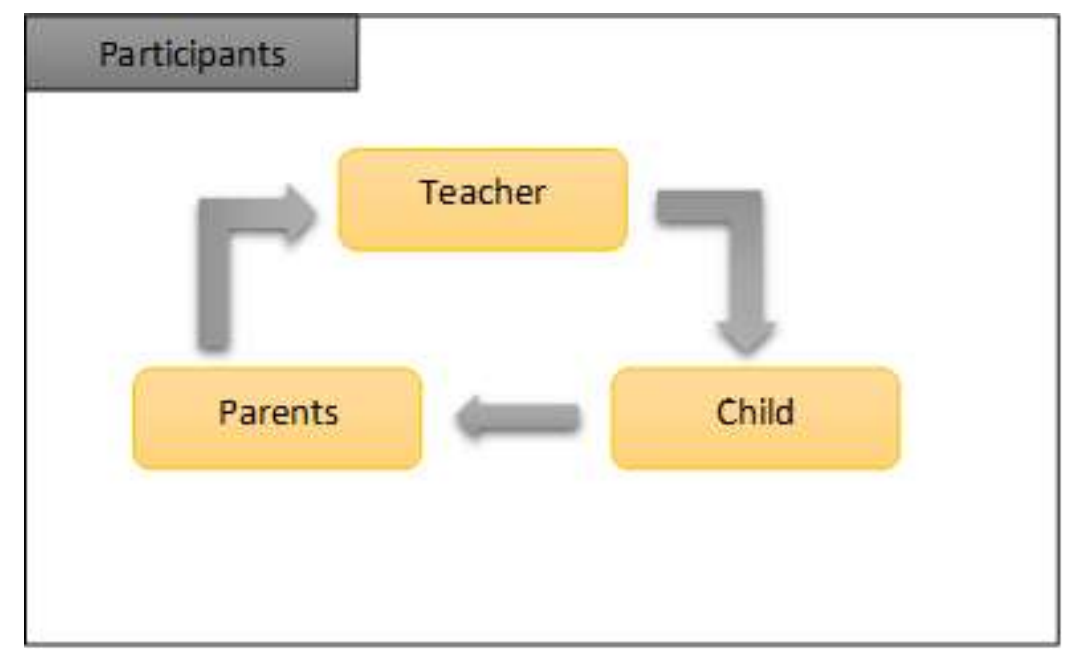

Figure 42: Participants Component

In addition to that, with a vary individuals with autism skills set and learning requirements, the traditional approaches APA and TEACCH would be lack of productivity in the learning environment specially when we have a large number of enrolment, and that encouraged the 
researcher to adopt the adaptive learning approach in this research which can be adapted for every individual learning needs targeting a more productive environment for all types of learners.

In this chapter the main users of the ACMLS Model are identified and can divided into two main categories: First category is the learner which is children with autism and second category is the educators such as teachers at schools and parents at home.

It is found throughout observations that these learners (Children with autism) are important to work closely with their teachers which use learning context reinforcement in most learning activities. Hence, the targeted environment is extended to include educator as another main user of the model.

\subsubsection{User Profile}

The user profile in ACMLS is a collection of personal data, abilities, education level, and learning style preference. This user profile will be considered as the user identity. This will help in personalising the prototype in terms of the colour scheme, font size, sounds and avatars to suite each user based on their profiles. These values can be set upon sign-up to the application by the teacher or the parent in the user profile page.

After submitting the profile data, and if all information provided are valid then will be stored in a data repository. These values of the user profile will be reflected on the user interface screen such as font size, colour scheme as well as the avatar used as animation guidance for the learners.

Lastly, hence the learner's personal privacy matters, therefore, the learner profile data will protected against unauthorized access to the system, and users are required to have login credentials for a secured login. 


\subsubsection{Teacher Role}

The teacher role is to identify the weaknesses or the areas to improve in every child, and implemented into the system in such away. The system look and feel must be customised to be comfortable to each child. The teacher therefore input the educational materials or topics into the system from the control panel section.

Teacher at the end of each session or assessment will be able to view the system feedback on the children progress for evaluation purposes.

\subsubsection{Children with Autism Role}

The children with autism are considered the end user in our system, they're the person under the spot light who is going to use the educations materials which been entered into the system by either the parent or the teacher. The child can access the system from anywhere at any time.

By adapting the adaptive learning technology into this study's model to assure that children are well engaged to the activities given or the tasks assigned to them. Adaptive learning approach will be discussed further in the design section.

\subsubsection{Parent Role}

The parent-teacher relationship, the parents will be able to use the system such as to input certain real-life activities or situations into the system whereas the child can undergo through the educational materials or assessments, this is to cope with home-life aspect. The parent role at home is mainly to complement the teacher role at school. Whereby the teacher concerns more on the educational materials based on curriculum and the parents concern is into the life routine situations. 


\subsection{Technology Component}

$\underline{\text { Technology }}$ as an augmentation of human performance has been the core of this research for communication, contents and creativity as an attractive method to gain the autistics attention to the educational materials throughout an interactive system as Figure 3 shows.

As mentioned earlier that this chapter aims to produce an interactive, web-based system to assess teachers and caregivers at schools or rehabilitation centres and parents at home as an alternative and complementary way of presenting the learning materials for children with autism.

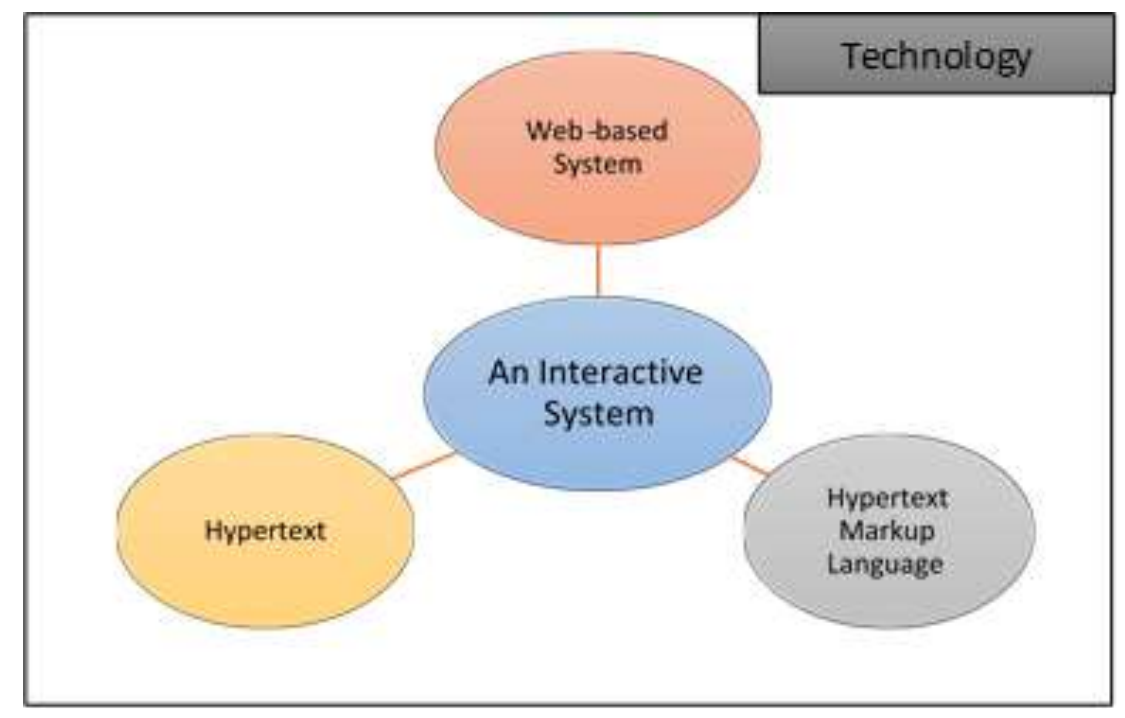

Figure 3: Technology Component

\subsubsection{A Web-Based System}

The Web is a term used to refer to the World Wide Web (WWW), or W3 (Vora \& Helander, 1997). Essentially, the Web is "a collection of protocols and standards used to access the information available on the Internet" (Vora \& Helander, 1997, p. 899).

There are three standards which assist the functioning of the Web: Uniform Resource Identifiers (URIs), which provide a mechanism for locating information, Hypertext Transfer Protocol 
(HTTP), which provides a mechanism for transferring information, and Hypertext Mark-up Language (HTML), which is a language for displaying information (Vora \& Helander, 1997).

It was demonstrated in the preliminary study chapter (section 3.4.5 and Section 3.4.6) that children with autism are comfortable and show excitement expressions using computers, as suggested by (Attwood, 2004; Bell, Cihak, \& Judge, 2010) computers offer many beneficial features and reliable results for individuals with autism and it has many advantages over the traditional rehabilitation methods (Epstein \& Klinkenberg, 2002; Evans \& Mathur, 2005; Fricker \& Schonlau, 2002; Gosling, Vazire, Srivastava, \& John, 2004; Umbach, 2004; Wilson \& Laskey, 2003).

Nonetheless, taking in consideration the other participants into the system such as the teacher at school and parents at home, it was anticipated that a web-based system would be feasible and facilitate the access from anywhere and anytime.

Main reasons for considering a web-based system are: Firstly, the knowledge and information to be taught to individuals with autism can be created via the system to demonstrate a real-life scenarios, schools subjects such as: English, Math or any other subject reflecting a range of activities that occur during the school day. Furthermore, adding interactivity feature to the system would make effective and efficient to grab the user's attention in order to complete the tasks. Secondly, the web-based system offers a potential platform to the teachers, caregivers or parents whereas they will be feeding the system with the educational materials. Moreover, they can manoeuvre the animations usage and the colour scheme to suite each child. Thirdly, autism centres operate daytime and children have to go home, therefore, there is a need for an application which can be accessed both at school and at home. Furthermore, an application to be easily updated and maintained frequently by the teachers or parents. 


\subsubsection{Hypertext Mark-up Language}

As mentioned earlier, HTML is a language for displaying information on the Web. It does this by describing the logical structure of a hypertext document in such a way that it is understood by the web browser, which then processes the information and presents the document on the Web (Vora \& Helander, 1997). HTML is based on Standard Generalised Mark-up Language (SGML), an international standard "for defining mark-up languages. Authors mark up their documents by representing structural, presentational, and semantic information alongside content. HTML is one example of a mark-up language" (Khurana, 2001, p. 12). HTML can be created using a variety of tools. For example, a plain text editor such as Notepad can be used to write HTML from scratch, while more sophisticated authoring tools such as Microsoft FrontPage and Adobe Dreamweaver offer a 'What You See Is What You Get' (WYSIWYG) environment (Khurana, 2001).

\subsubsection{Hypertext}

There is no clear definition of the term 'hypertext' (Horton, 1990; Rada \& Diaper, 1991; Vora \& Helander, 1997). Typically, hypertext may refer to one or all of the following processes: information creation, information storage and management, and information presentation and access (Vora \& Helander, 1997). In order to understand the meaning of hypertext, a comparison to traditional text should be made (Nielsen \& Nielsen, 1995). Traditional text follows a sequential structure, with a linear sequence determining the order in which the reader looks at the text; hypertext on the other hand has a non-sequential structure, that is, there is no specified order in which the text should be read (Nielsen \& Nielsen, 1995).

Hypertext presents several different options to the readers, and the individual reader determines which of them to follow at the time of reading the text. This means that the author of the text has 
set up a number of alternatives for readers to explore rather than a single stream of information (Nielsen \& Nielsen, 1995, p. 2).

Hypertext applications have many beneficial features. For example, large collections of materials in varying media can be assembled and linked using hypertext (Vora \& Helander, 1997). In addition, hypertext facilitates the organisation of information in multiple ways, making crossreferencing of information easier and allowing multiple authors to combine information, promoting collaboration (Horton, 1990). These factors were considered relevant for this particular study where various forms of information were required to be organised and presented, and where several people might be responsible for authoring materials. Other benefits of hypertext include the fact that it can be controlled by the user and it has the potential for savings to be made on physical storage space and also on updating information (Nielsen \& Nielsen, 1995), features which were important considerations for this study.

\subsubsection{An Interactive System}

It is commonly acknowledged that education at school consists of various activities which take place during the day, however those activities make the environment static in terms of the participants and the educational materials. Therefore, an interactive system is considered to fit in to illustrate and cop a dynamic environment which requires the individuals with autism to use daily with the assistance of the teachers and the parents in uploading different types of assessments.

A variety of different media formats are combined to present information and to facilitate communication between the user and the computer system. For example, interactive systems may include a mixture of graphics, text, sound and other media formats, which contribute to making the interaction an interesting and pleasant experience for the user. The aim of an interactive system 
for children with autism is essentially to gain their attention when communicating and using the system, moreover, applying the CCI design principles in the interactive system that implies an exciting involvement in the way the information is presented, retrieved and interacted with (Gillham \& Buckner, 1997). Nevertheless, to aid a user in accomplishing goals from some application domain. A domain defines an area of expertise and knowledge in some real-world activity (Patel, Yoskowitz, Arocha, \& Shortliffe, 2009).

In order for interaction and communication to take place there needs to be an interface to mediate between the user and the computer system; this is commonly referred to as the 'Human-Computer Interface' (Faulkner \& Faulkner, 1998). The interface is, therefore, an essential element in the interaction process, as it operates as a translator for both the user and the computer system. For a successful interaction to occur the interface must be able to facilitate an adequate translation.

\subsection{Design Component}

Design The concept of design is the formation of learning resources in a systematic way with the employment of the design principles and the visual design in order to culminate the ultimate innovation image of the educational organisations.

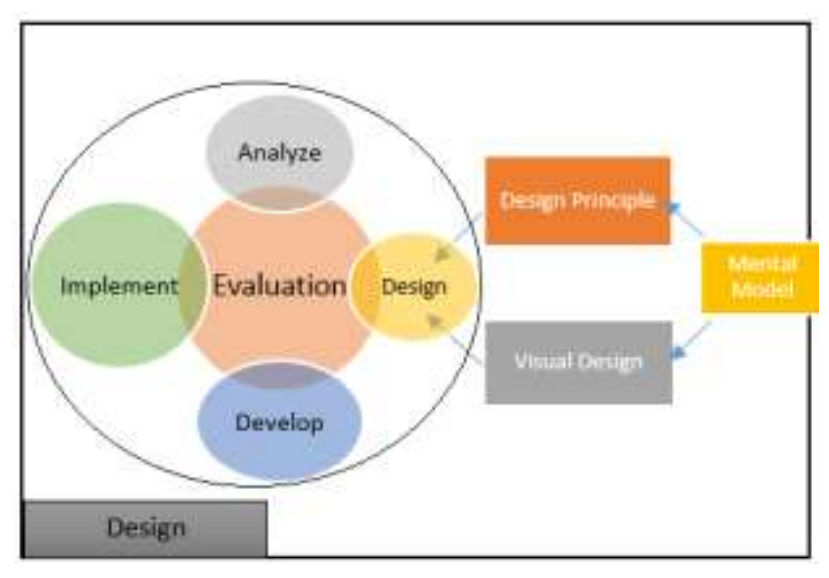

Figure 44: Design Component 


\subsubsection{Instructional System Design Model}

Instructional System Design (ISD) model serves as a guide in developing ACMLS model. There are different approaches to ISD but all have the basic concept of ADDIE, which is the acronym for the five phases as shown in Figure 4 (Analysis, Design, Development, Implementation and Evaluation) as a systematic approach of designing an instructional system. Each of the components in this approach has its relevance in the design process. The brief description of each phase is given below.

Analysis: This phase comes first in the systematic approach in developing an instructional system. The major activity in this phase involves creating a user profile for the instructional system and understanding the general requirements of how to achieve the learning objective.

Design: This phase deals with the presentation of the learning objectives, contents, subjects, assessments, exercise and quizzes in order to achieve the aim and goal of this study which is provide children with autism with an alternative learning system instead of the traditional methods and provide caregivers with a gateway manage the materials given to the children as well as an administration privileges to monitor learners progress.

Development: This phase focuses on the creation and the content assets assembly which is described in the design phase until the production of the application as an outcome of the analysis and design phases.

Implementation: This phase involves the experimental stage where the developed system is used by the targeted users.

Evaluation: This phase checks the effectiveness of the developed system by taking certain measurements and feedbacks. 


\subsubsection{Design Principles}

Michaud, Duquette, and Nadeau (2003) found that it's so important to adhere the design principles which take the key characteristics of autism character in consideration while the system or the prototype development.

Design principles to consider in designing ACMLS model such as:

- Images and photos are a more effective way of representing an object or event than words for children with autism. In addition, the device should use simplified short messages (three words or less) which are frequently repeated to support learning. Messages should also refer to concrete things rather than abstract thoughts and concepts.

- The design of ACMLS model should take in consideration the individual differences of the children with autism who are going to use it, each individual has certain needs and requirements which should be addressed and taken care of so to be a successful intervention.

- The inclusion of parents input into the ACMLS model is to use it at home, which will help in intensifying the intervention for the children. Parents will be given the accessibility to add and upload educational materials to the system.

- The colour scheme of the system should not be anxious to children. According to (Autism Speaks, 2011) children with autism may show sensitivity to certain colours. Therefore, a control panel will be designed for parents and teachers in order to customise the front-end system to the liking of the child.

\subsubsection{Visual Design}

As mentioned earlier the use of multimedia in learning involve of the usage of text, images, animation and audio as a medium of knowledge transfer to learners. Multimedia can be referred 
to the text representation in a written, audio or animation and videos (Mayer, 2005) which can be referred to the mental model or construction form from a given multimedia representation (words, audio, pictures and animations). Multimedia elements to be considered when constructing or building a multimedia learning medium (ACMLS) for teaching children with autism involves of:

- Symbols can be used as an alternative representation to text (Leach, 2010), although it is important that there are concrete representations due to children with autism struggling with understanding abstract concepts.

- Children with autism can have problems understanding abstract concepts; so abstract metaphors should be avoided (G. Mesibov, Thomas, Chapman, \& Schopler, 2007), graphical representations should be as realistic as possible (Leach, 2010).

- Children with autism can exhibit even greater difficulties with reading and so text should be kept to a minimum (Leach, 2010) and their strength for visual processing incorporated within the design wherever possible (Barry \& Pitt, 2006; M. Davis, Dautenhahn, Powell, \& Nehaniv, 2010; Van Rijn \& Stappers, 2008).

- The use of certain sounds can trigger anxiety in some children with ASD who have auditory sensitivities and so should be used with caution (M. Davis et al., 2010; Leach, 2010; Putnam \& Chong, 2008), ensuring there is an option to turn sound on and off.

- Colour schemes should be kept simple for children with autism, with the option to change colours, for example the background colour to reduce contrast with text and aid reading (Leach, 2010).

- As mentioned earlier it is important to consider sensory issues when using animation, sound and highlighting through different colours when designing for children with autism (M. Davis et al., 2010; Leach, 2010; Putnam \& Chong, 2008), particularly if being used in conjunction 
with one another as they can struggle to know where to direct their focus (M. Davis et al., 2010).

\subsubsection{Mental Model}

A user generally has certain expectations about the behaviour of a computer system and this is typically referred to as the user's mental model (Allen, 1997; Faulkner \& Faulkner, 1998). This type of model exists in a person's head and so obviously it is not possible to see such a model (Allen, 1997). People form their mental models of systems through experience and training (Norman, 2014). In complex situations people tend to make inferences based on prior experience, developing mental models dynamically to help them cope with a new or difficult situation (Preece \& Rombach, 1994). Therefore, “the user's mental model of an information system has a critical impact on the user's ability to use systems effectively" (Chen \& Sharma, 2002, p. 51). Unfortunately, mental models formed by users are frequently vague and incomplete and it is, therefore, important that the interface of a computer system is designed in such a way that it facilitates the attainment of an accurate model of the system by the user (Faulkner \& Faulkner, 1998; Preece \& Rombach, 1994). Autistic children experience significant difficulties recognizing existing and non-existing mental states from their textual descriptions. Conversely, controls easy distinguish the possible mental states and their recognition serves as a useful exercise on the way to learning the complex mental states (Brewer, Young, \& Barnett, 2017). A means of assisting a system designer to demonstrate a potential system and facilitate the user's mental model is through development of multimedia presentation styles as mentioned in the visual design section would positively assist in building the mental model for children with autism. 


\subsection{Education/Learning Component}

Education/Learning The concept of education is concerned with the learning styles, objectives, strategies and methods, Figure 5 shows also the adaptive learning which accomplished throughout the learning methods used to develop the educational materials, hence the cognitive model is concerned of the students' state of mind and as mentioned earlier the low cognitive abilities of children with autism, therefore, multimedia strategies and perceptions and problem solving strategies must be implemented in the materials for an effective learning process.

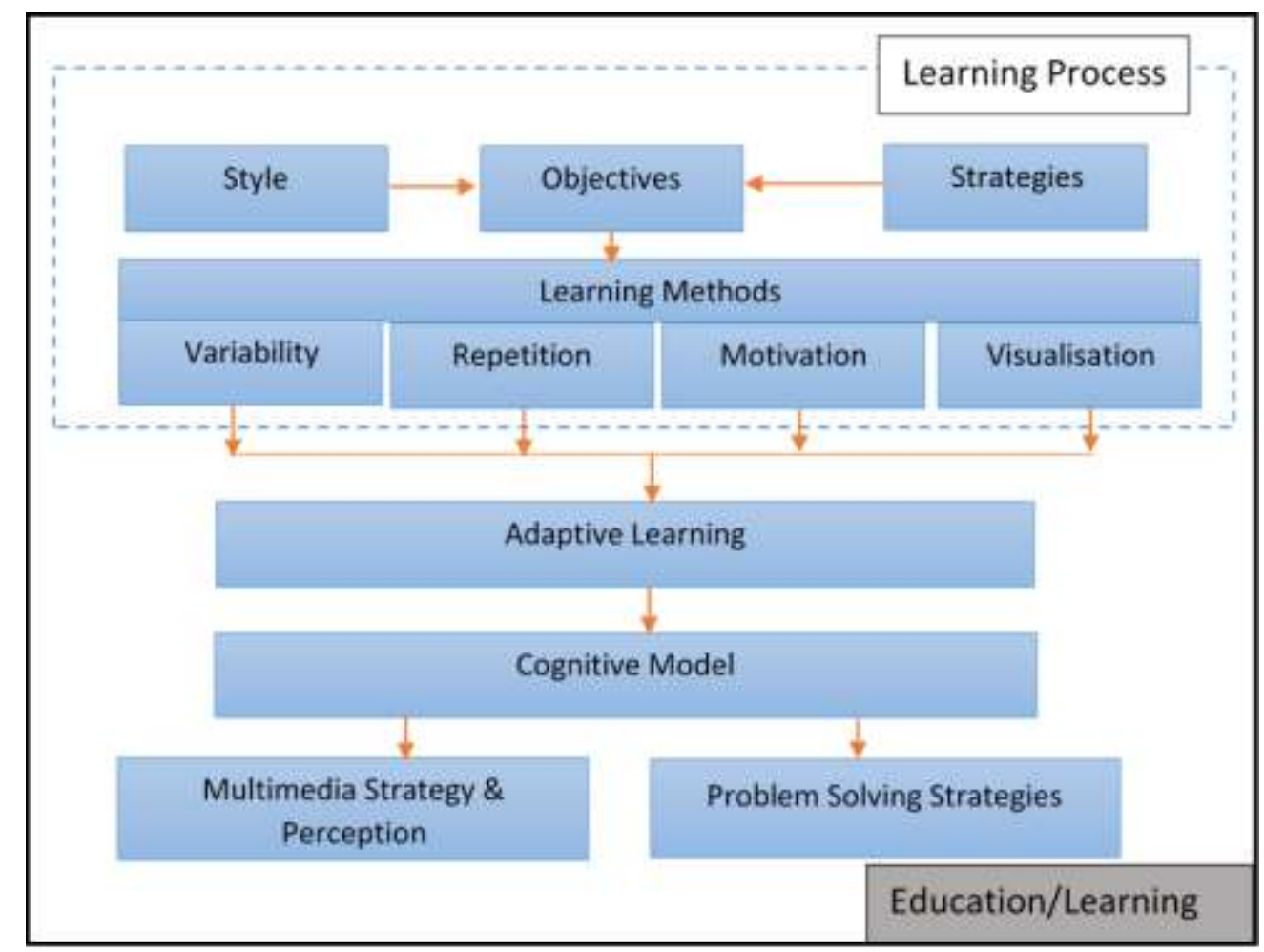

Figure 5: Education/Learning Component

\subsubsection{Learning Objectives}

Defining the learning in objectives helps mainly in the learning system design and to keep the focus of the learning system model main goal so that do not deviate from the main objective. And as a learning major objective is set to educate children with autism and get the fullest attention 
towards the educational materials presented to them at school by the teacher or caregivers and at home by the parents. And in order to do that; the design principles have to be present in the learning system design process.

As mentioned earlier in the literature review chapter that children with autism have a very low cognitive skills compared to typical children. Therefore, children with autism require a simple visual presentation of what to be learnt by using pictures for example to represent an action or information which needed to be delivered to children instead of using an abstracted text presentation. Picture Exchange Communication System (PECS) as an example of how the information or actions been presented to children with autism.

As mentioned earlier that the main objective of this research is to design and develop an adaptive content management learning system and then evaluate its effectiveness and efficiency as a new assistive technology intervention approach for children with autism. In addition to that learning presentation style is a main factor that influences the children attention towards the materials.

\subsubsection{Learning Style}

Learning style is the component that assists in the achievement of the learning objective, it is considered the main factor that can influence the learner interests and progress. And due to many different learning styles available according to S. E. Davis (2007) such as: Visual, Aural, Verbal, Physical, Logical, Social and Solitary. The variability of the learning styles adds effectiveness to the learning tools so it cope those different styles to keep the children level of attention as high as possible to the learning materials. None of the mentioned learning styles earlier considered as the best style to be followed to educate children with autism due to the individual differences among 
them. Hence, it would rather depend on what is applicable to each learner which might not be suitable to another.

The representational style is considered in this research to present the educational materials or contents with a simple picture for example using ball picture to represent "I want to play" while other contents have to be presented in a decorated textual form. Audio is considered as add-on feature to the textual forms of presentation. This indeed required when it comes to learning Quran verses (Banire, Jomhari, \& Ahmad, 2015). And as mentioned earlier the objective of this research is to come out with ACMLS model for children with autism which can help in teaching vary number of topics with the help of the teachers or parents.

Contents presentational style is the method of presenting the contents to children, and as illustrated in the literature review chapter the different interests of the children with autism and their cognition abilities. Therefore, different presentational styles are considered for educational material such as:

\section{Video Presentational Style}

Video presentational style could be referred to as a live scene of the context of a message or content to be taught. This visual style is considered in this study in order to facilitate comprehension in learning. The video presentational style is adopted from video modelling technique where it is used for content illustration in learning for children with autism which supports their needs for real scenarios (provide them with selective attention) in certain elements in the visual display (McCoy \& Hermansen, 2007). The use of video modelling in children with autism has been effective in relaying a message to them. 


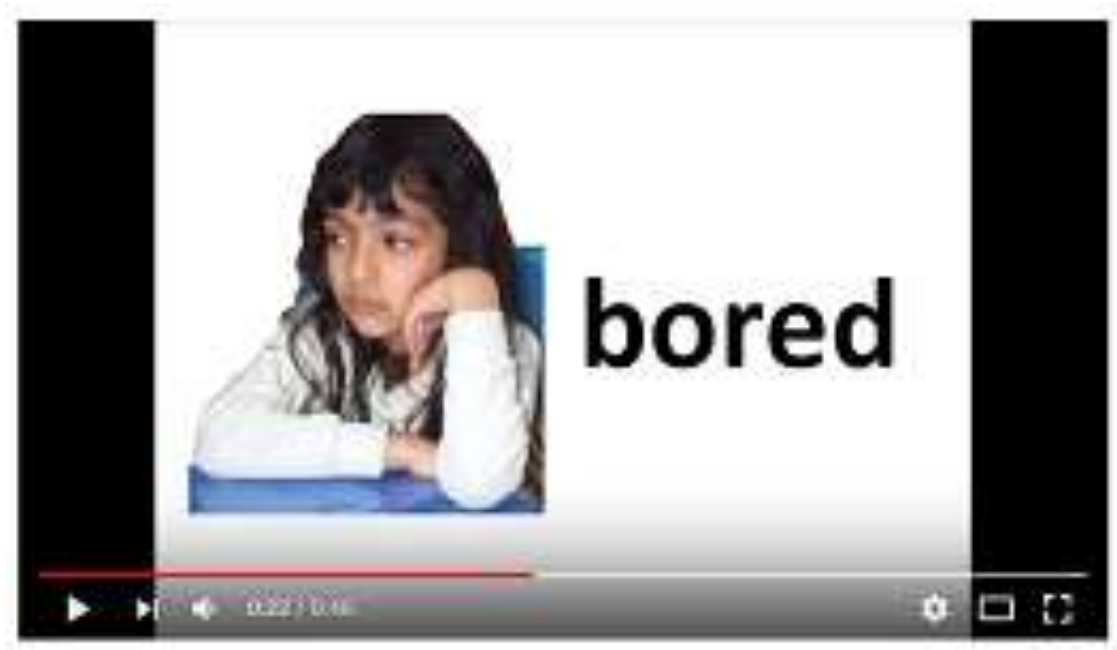

Figure 4.6: Video Modelling

Video modelling as showed in Figure 5.6, it involves the real life visual display to the targeted learner without any interruption while watching (Sigafoos et al., 2007). The types includes: include Video Self Modelling (the use of the learner's image as element to get attention) (Robson, Blampied, \& Walker, 2015; Whitlow \& Buggey, 2003), Scene view video modelling (the use of scenario or scene of an event) (Moore et al., 2013) and Point-of-view video by (Hine \& Wolery, 2006; Tetreault \& Lerman, 2010), to explain the how to prepare an afternoon snack to a 4 year old child with autism. This process involves the use of exact action that is to be done by the learner in sequential steps. This method was effective in training this child, although he was sometimes guided by prompts. All of these types of video modelling are effective as a means of intervention in children with autism. However, the use of Scene view video modelling could be used as a general representation of an event. This kind of video modelling does not represent the whole information but part provides part of the information that can represent the whole information. Hence, Scene view video was adopted as one of the Learning Method.

\section{Transitional Image}


The use of static image involves the use of picture that could be used to further illustrate a text or action. According to Morrison, Ross, Kemp, and Kalman (2010) the use of a picture or animation was identified as the best way to facilitate learning in children. There has always been the debate on which is better when animation and static images are used in teaching children with autism. There are some studies that support the use of static picture as the best way to enhance learning. Static picture keeps the information to be conveyed permanently where the learner can always refer back to the message unlike the animation that transits and does not leave the image or scene for a long period of time in order to be mastered before it disappears (Hegarty, 2004).

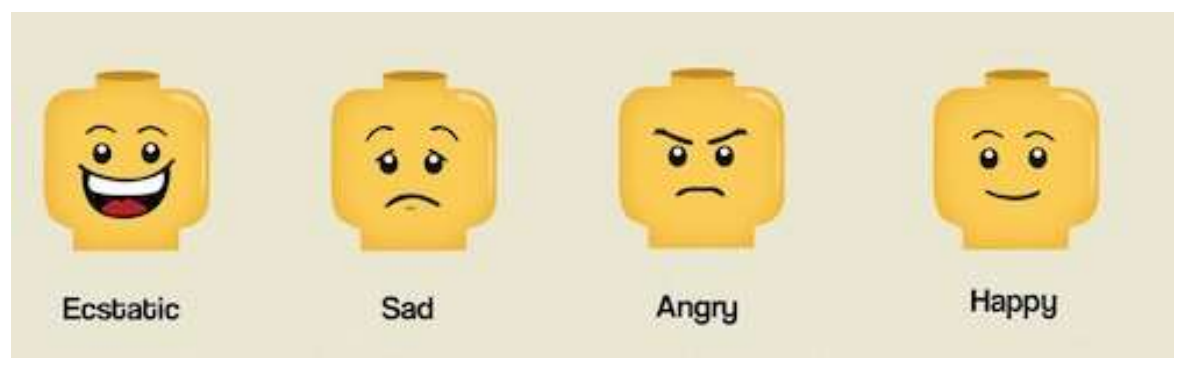

\section{Figure 4.7: Static Picture Presentation}

However, the use of static picture as seen in Figure 5.7 could be a best way of communicating message in learning but this does not go well with children with autism because they require stimulating effects to keep their attention. Static pictures appear boring to them that they give little or no attention to it.

According to one of the teacher, he said: The use of static pictures in a transitional manner attracts the children with autism more rather than static fixture.

More so, it has been observed in the preliminary study that some children with autism are obsessed with the movement of the fan, they also very attentive to systemizing toys such as train (Golan et al., 2010). 


\section{Humanoid Animations Style}

Animation and colourful images have the features to attract the attention of learners especially children with autism (Doyle \& Arnedillo-Sánchez, 2011). The findings showed that $90 \%$ of the learner with autism benefited from this mode of presentation as compared to other modes such as video, image and audio. It is quiet easy for learners to put the content of the lesson into memory because of its illustration effect. However it may require high processing memory (cognitive skills) for some learners with autism. Hence, this mode of presentation might need to be extended in order to cater for other learners.

\section{Decorative Style}

The decorative style means abstract visual representation of the learning content. It does not present the visual meaning of the learning content but provides a stimulating effect as used in sensory room for visual stimulation. It consists of only one method of illustration which is abstract animation.

\section{Sad Happy Angry Surpprised}

\section{Figure 4.8: Abstracted Decorative Style}

The abstract dynamic image is referred to as the animation of multiple colours as seen sensory room. This stimulus has been effective as a visual stimulation for children with autism as it calms them and gives them satisfaction. This dynamic multiple colours can be perceived by these children as visual stimulations that attract their attention. Since there is no information to be processed from this visual, the need for cognitive ability will be less required. This effectively 
makes the children focus on the screen that has the displayed colourful text (see Figure 5.8) due to the high perceptual load which is responsible for reduction of cognitive load. This is in line with load of theory and attention as well as cognitive control (Lavie, 2010).

\subsubsection{Learning Strategies}

The learning strategies of the ACMLS model are focusing on how to achieve the learning objective which was set, and throughout the learning styles. Morrison et al. (2010) suggested that those strategies should be followed in an instructional design and based on learning styles (refer to section 5.2.4.2). These strategies are:

1. Colourful pictures: children with autism showed an attraction to colourful pictures and objects. This will help them to pay more attention.

2. Simple illustration: teaching contents with simple illustration helps children with low cognitive skills.

3. Contents repetition: as one of the children with autism characteristics or rather strength is they have the repetitive behaviour or action, therefore, they like the repetitive actions which help them to pay attention to the given tasks.

4. Animations: children with autism are attracted to the animation characters, it helps too in increasing their attention level.

5. Short lessons: children with autism have anxious to the long duration of a learning sessions. Therefore, a short lesion duration is a good method to be followed in order to achieve the learning objective.

6. Clear and colourful font: this helps the children to read clearly and noticeably, and by making the text colourful that makes pay attention to the given learning text. 


\subsubsection{Learning Methods}

Learning methods are the various ways the learning objective can be reinforced in order to achieve the goals. Four types of methods are proposed after interviewing teachers, parents and from observations during the preliminary study. These methods are: Variability, Repetition, Motivation, and Visualization.

\subsubsection{Variability - progress}

Variability is a key component in children's learning and development. Variability is suggested for better acquisition in children with autism learning, by accumulation of instances of particular words, information presentation and situations structure. This should assist children cognitive skills ability growth for instance: by presenting a certain situation in diverse ways to children should provide a more complete sample of possible forms of reactions. Another example is language presentation to children in different ways and forms provides a larger sample of possible expressions when used to form a sentence.

\subsubsection{Repetition - Memory}

Reinforcement should be encouraged in any learning application for learners with autism as it enhances their learning. Reinforcement also aids the memory in adapting to the content better. There are two principles that can be used to aid incorporation of content especially when the learners are slow in learning or the content is strange to them. The principles are principle of organisation and principle of repetition (Alessi \& Trollip, 2001). The rule of repetition is considered as one of the learning strategies because one of the strengths of children with autism is rote memory which supports repetition (Quill, 1997). They like to repeat things and are intent by repetition. In addition, repetition was one the ways the speech therapist uses in emphasizing the learning content to children with autism in mostly all autism centres or schools. The principle of 
organisation also plays a good role in presenting the content. The content should be presented in such a way that the children are motivated with the first look based on the design principles and learning strategies which mentioned earlier.

Repetitive pattern of the content will enhance their attention and ability to retain the content. Repetition could also be considered as a way of making perception easier for learners (Alessi \& Trollip, 2001). Learners can be persuaded to repeat content of the module if repetition is used as part of the presentation and it aids learner in eventually mastering the content.

\subsubsection{Motivation - Reward}

Motivation in learning is imperative as identified by psychologist especially for learners with autism who always try to avoid learning or pay less attention. Rewarding learners always gives them the feel of progressive achievement. It has been chosen as a way of making the learning process interesting (Hulusic \& Pistoljevic, 2012).

\subsubsection{Visualisation - Presentation}

Visualisation as mentioned in the learning guidelines must be followed for effective learning outcome especially when children are the main targeted learners and based on their characteristics. Learning guidelines motivates and attracts the attention of the children during learning session for example plain text is usually ignored by average learners, therefore, in order to gain attention for those children with autism especially those with attention impairments, visual modes of presentation such as animated images and audio is used. This study made use of colour code as a way of animating the text and overall system appearance in order to fit the learners according to their profile such that the colour of the text changes as its being read in order to gain the most of the attention of learners to the educational contents. 


\subsubsection{Adaptive Learning Approach}

Adaptive learning approach is an educational approach, it uses the computers as interactive learning medium, and manages learners according to their unique needs. Computers as a learning medium adapts the presentation of the educational material and curriculum to help students according to their intellectual capabilities (Battou, 2017; Ibrahim, AlSharabi, Djemal, \& Alsuwailem, 2016).

Nonetheless, adaptive learning method as seen in Figure 9 attempts to transform the students from passive receptor of knowledge and information to a collaborator in the educational activity. It also provides valuable information and feedback to teachers and parents as one of its key features in order to use it in a more constructive way.

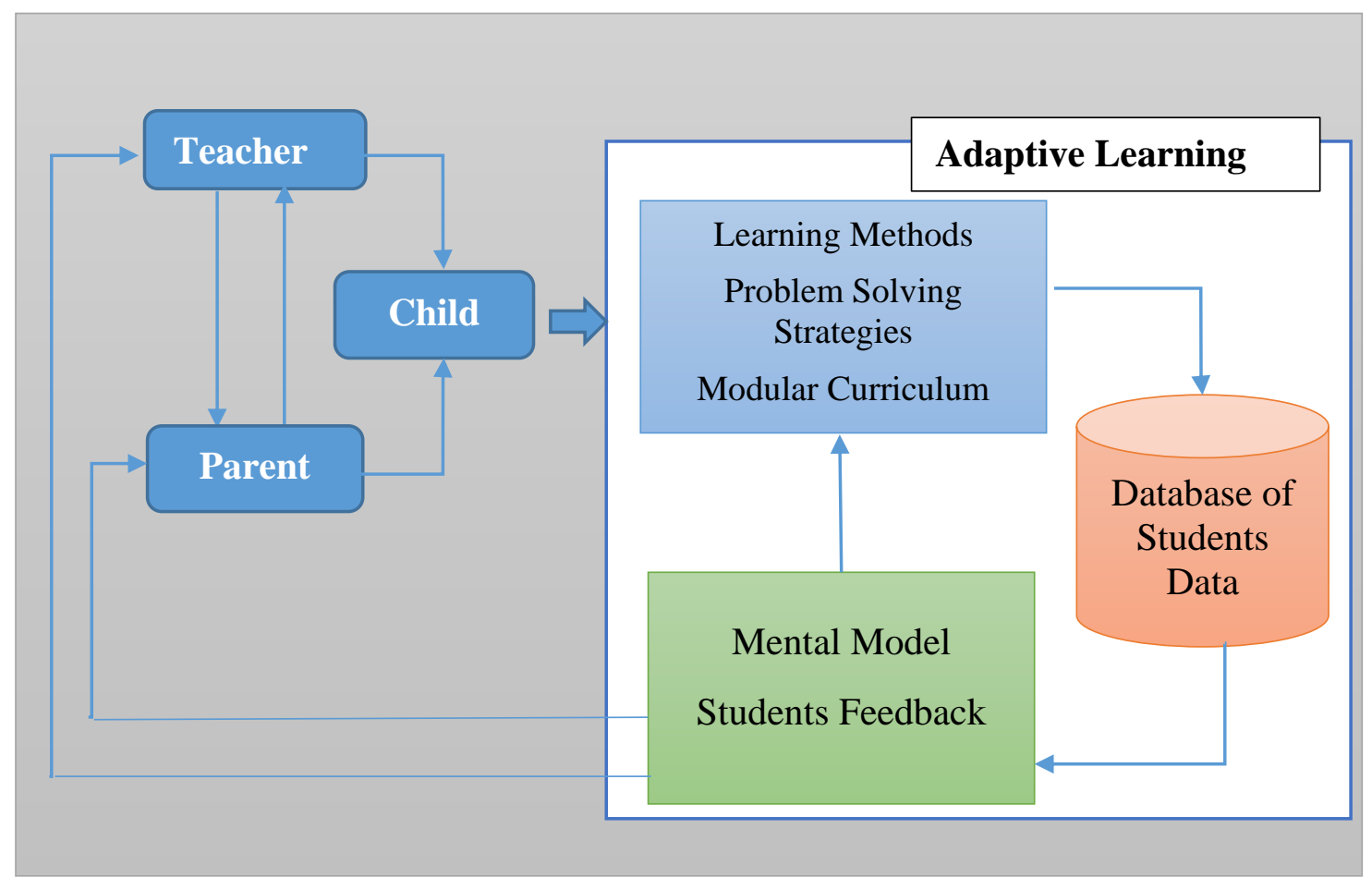

Figure 49: Adaptive Learning Flow 
Kerns (2013) listed many benefits of using adaptive learning technology such as:

Can be customised to Fit All Learning Levels Adaptive learning can be personalized learning system which adapts to all learning capabilities. The teacher needs to set the parameters for each individual for the first time and save it as part of the learner profile. When the learner starts using the adaptive technology approach, it will detect what difficulties or hardship the learner is facing and store it in the database as a row data and send a feedback to teacher as part of the learner progress.

The learning style used in this approach is flexible style whereby the learner can use different strategies to solve the presented problems such as textual, verbal, and visual or animation presentation. So that learners be able to achieve the learning objectives and pay closer attention to the given tasks and materials.

Provides Real-time Feedback Adaptive learning technology is designed to: Firstly, collect learner immediate response or answer to the presented problems. Secondly, learner while answering will prompted with an indication of whether the answer is correct or wrong. Lastly, send the learner's answers to the parents or teacher as a feedback and part of the learner progress. By keeping track of each learner, teacher or parents will have a better vision for a future tasks to be given for those who're facing difficulties getting past one lesson or a task.

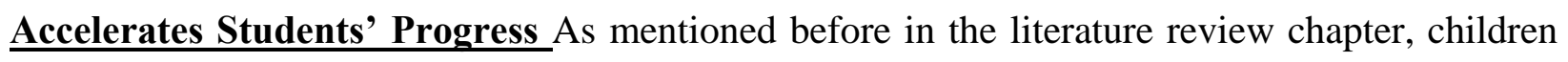
with autism are varying in skills impairments and learning pace. Therefore, it becomes so difficult to design a 'one size fits all' concept. However, adaptive learning technology helps to design educational materials based on the CCI concepts in section 2.7 aiming to gain the learners attention 
and faster progress. This way, every learner benefits from the assessment equally and no one is left behind.

Helps Teachers Become Better Educators Adaptive learning approach tends to balance between the face-to-face instructions and the online instructions. It does not mean adaptive learning meant to replace the educators, it just help to initiate a self-paced guidance system and build up the independence aspect into the learners.

Keeps Students Engaged and Motivated Hence the technology is playing a major role in education nowadays, as well as the children with autism are showing an interest in technology. Therefore, the adaptive learning approach is a motivation factor in the learner's life. Consequently, children can become more engaged with the educational materials or the tasks assigned to them via the system in order to achieve it aiming to a better scores and understanding.

\subsubsection{Cognitive Model}

Literature has shown that children with autism have low cognitive ability and information processing skills as compared to typical children, they have difficulties in interpreting or understanding the thoughts and feelings of other people, may have difficulty with empathizing and often feel confused by other people's behaviour (Baron-Cohen, 2000; Ozonoff \& Miller, 1995). Hence, they require simple visual illustration for information processing by using a picture to present an action in information given rather than representing the whole information for example the PECS (refer to section 2.4.1.3).

Children with autism prefer the visual presentations with less information details which empower the learner's state of mind to absorb the information and lead to a faster information processing rather than detailed visuals which may confuse them and disturb their behaviour. 


\subsubsection{Multimedia Strategy and Perception}

The way and manner learners perceive and attend to information are key factors in achieving a meaningful learning. However, attention of children with autism is not easily achieved. Thus, there are different principles to be followed for different components such as text, picture, audio and background of the presentation style (Alessi \& Trollip, 2001). The principles are:

a. Information should be simple and easy for perception.

b. Dynamic approach should be adopted in order to attract and sustain attention in learning.

c. The position of the relevant content should be conspicuous.

In order to enhance the learner's focus and attention, the font size and colour should be considered, the audio should be clear and audible and the picture should be clear and attractive.

According to Wise (2014) listed other principles to be considered in addition to the above list:

1. Predictable action: system designers are advised to let the child know what will happen next. For example, "After you finish the dinner, it is time to brush your teeth", or "In five minutes it is time to turn off the computer and start your writing assignment". And in order to selfmonitoring a timer should be placed within the application or the activity such as a countdown timer. So when they are given a task or assignment they do better if they know when the task will end.

2. Avoid loud sounds: many children with autism are audio hypersensitive so it's important to avoid loud sounds.

3. Set expectations, be consistent, and follow through, by making a routine activities. Children with autism have the challenging behaviours so in order to avoid that action should be predictable. An example of predictability would be having a set routine each night. 
4. Acknowledge the child or students for complying such as praising or rewarding when complying with the rules.

5. Tell the child specifically what you expect and allow him to earn privileges for complying with your expectations

6. Give Choices, children in general like to feel a sense of control over their world. Hence, we are dealing with children with autism in this study. Therefore, limiting the choices to two to four options is beneficial, as may get overwhelmed with too many choices and cannot decide.

\subsubsection{Problem Solving Strategies}

This form of knowledge is the basis of analysis and creativity and may involve the application of mental models. I argue that the key capabilities are those of recognition, open-mindedness, backtracking and re-formulation. My own work in this area resulted in a published paper to identify the steps that the learner would need to undertake to formulate computer models (Millwood \& Stevens, 1990), based on the experience gained in formulating the Modus project to design modelling software:

- Identifying a purpose;

- Having concern for presentation and communication;

- Constructing an interactive simulation;

- Picturing the end-product;

- Identifying elements;

- Characterizing elements;

- Identifying relationships and

- Characterizing relationships. 
Even in the higher, informal and professional sectors of education, complexity of education is matched by complexity of learning outcomes which may include:

- Skills development;

- Knowledge acquisition;

- Improvement in strategic, analytic and creative capacities;

- Attainment of competence;

- Establishment of attitudes and values.

Each of these societal purposes and these learning outcomes demand different approaches and understandings for the theorist and may develop at varying rates or found to be diverse in relation to context, location and culture (Felder \& Brent, 2005).

\section{ACMLS Learning Process}

Learning process as Figure 12 shows, it starts with participants component (teacher or the parent) as the ACMLS model shows in Figure 1 by identifying the learning objectives such as mathematics, facial expressions and emotion or any desired subject to be taught to the learners, identifying the learning objectives shall make the learning process a goal oriented rather than deviating away from the main objective for starting this process with learners. The learning styles as mentioned earlier are to assist in achieving the learning process objective such as video presentations, transitional images, humanoid animations or decorative styles which are determined by the teacher or the parent. Followed by the learning strategies as a presentational guidelines to the educational materials.

Specifying the materials or the contents which are required to educate the children and applying the learning methods based on the education/learning component (refer to section 5.2.4) on the 
educational materials such as the variability of the contents to assist children cognitive skills and learning progress, repetition and reinforcement of the contents to enhance the child's memory, motivation after an achievement which contributes in attracting children to the contents and gives the feel of progressive achievement while learning, and the final learning method is the visualisation which is the contents presentation taking in considerations that the targeted users are autistics with low cognitive abilities as compared to typical children. Therefore, a simplified visual illustrations of the learning materials and contents are highly recommended as discussed in the design component (refer to section 5.2.3).

Learning process is a task that has to be accepted by the targeted learners, they should be selfdetermined and willing to go through this process. The teacher or parents should observe the learners in order to build the learning environment which aims to empower learners and motivate them in the initial stages so that they could understand the learning process and tasks in order for them to use the system independently. Assessments and quizzes are given to the children at the end of each learning session to evaluate their learning progress. 


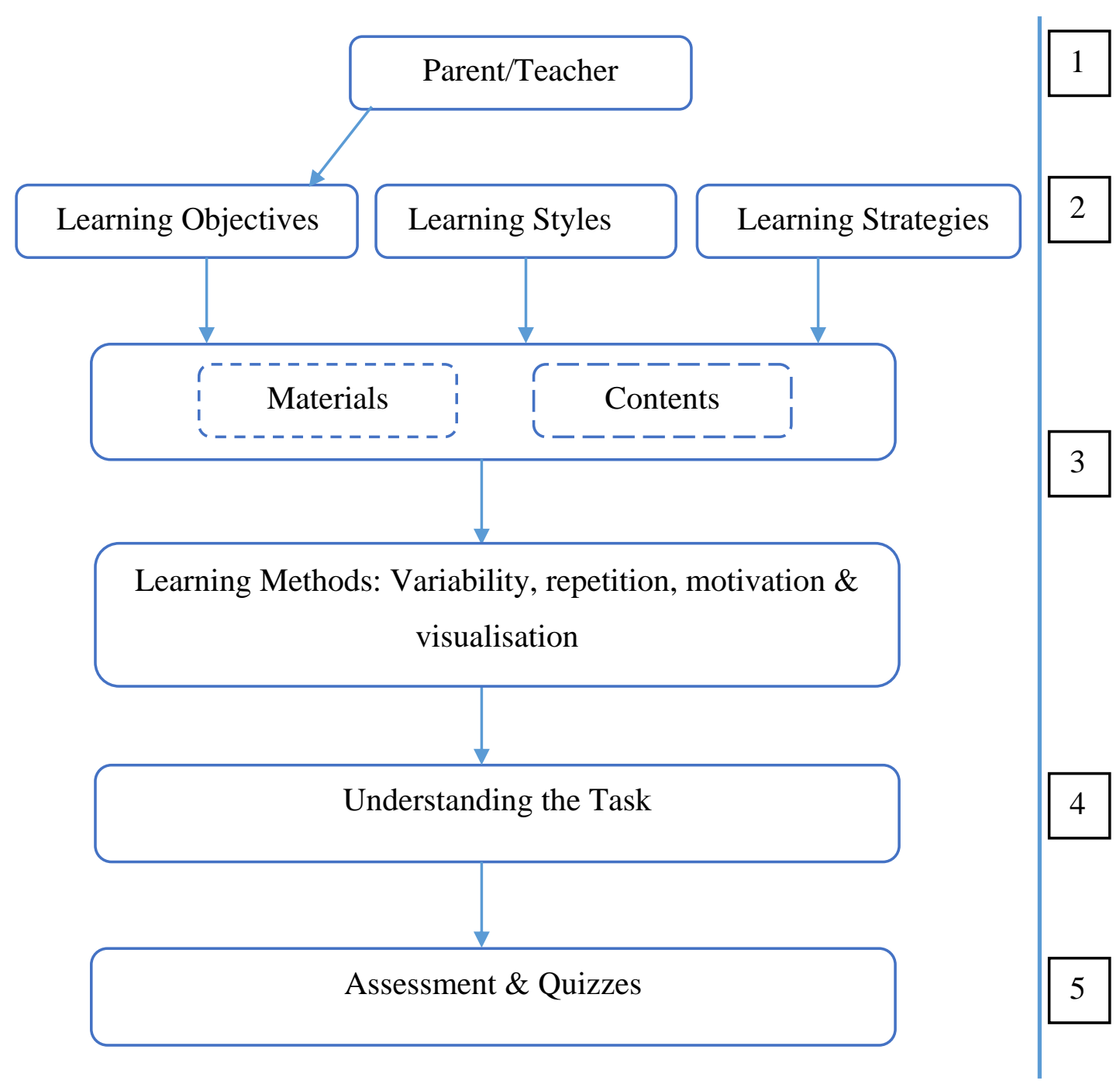

Figure 510: The ACMLS Learning Process

\section{System Structure}

The system structure which was finally implemented consisted of the following areas: a welcome page, a security login page, home page, learning entry page, a test/quizzes page, administration page, and a teacher/parents page. These areas are now discussed.

\subsection{Welcome Page}

The welcome page is to be the main entry point to the ACMLS system on the web. It was recognized that access would need to be restricted to participants so a security login was set up as 
shown in Figure 11. A login page was introduced in order to deter anyone other than participants from accessing the ACMLS application. Parents and teachers were provided with written details of the structure of the ACMLS application and were also issued with usernames, passwords, and instructions of how to login.

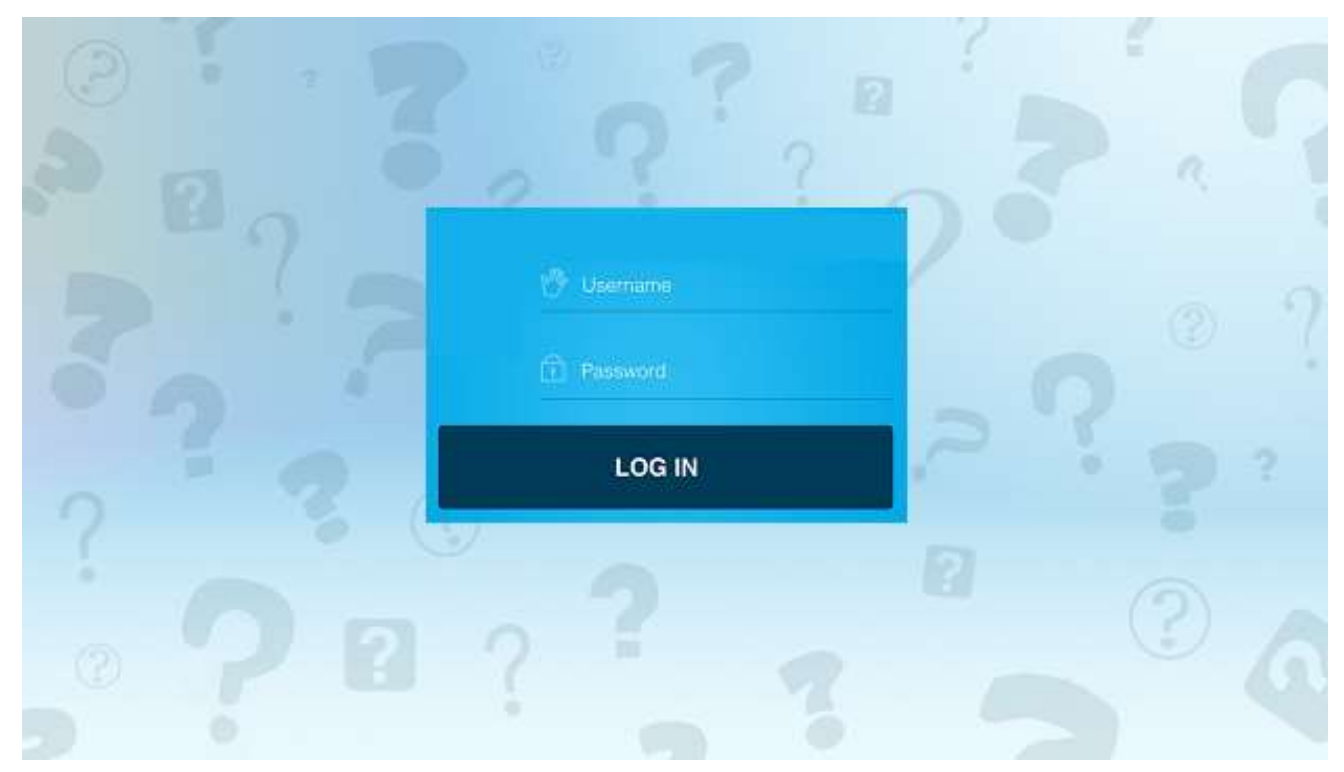

Figure 611: Security Login to the ACMLS System

The welcome page Figure 12 has two navigational links in the middle of the page; one link is to navigate the student/learner to the tutorial section which includes the lessons and educational materials which posted by the parent or the teacher and the second link is to navigate them to the test or quiz section. 


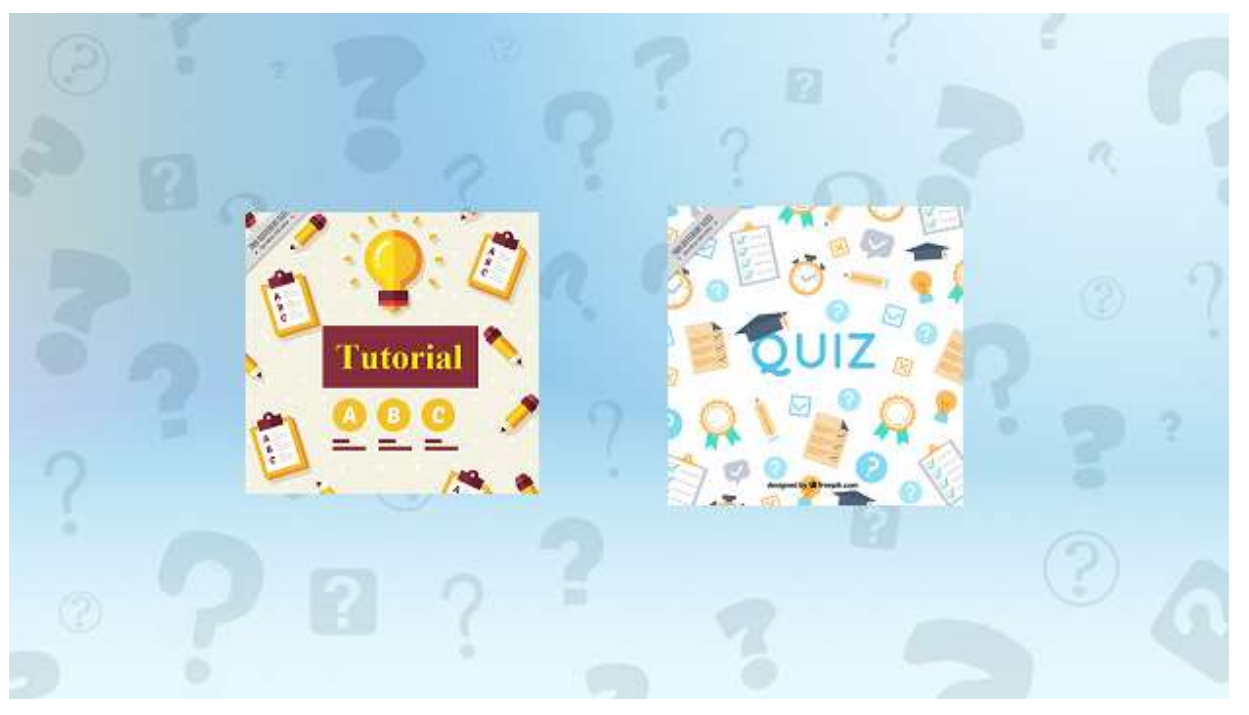

\section{Figure 12: ACMLS Welcome Page}

Administrator, teacher and parents can use the same login screen to login to their accounts, they system will detect the login ID and navigate the user to the corresponding screen. Administrator role in the system is to manage the users' accounts and generate statistical progress reports for students enrolled to the system. Figure 12 shows the home screen when learners login to the system, two main buttons so they can navigate to tutorials or quizzes.

\subsection{Learning Entry Page}

The entry page to the ACMLS application was set up very simply and direct to the main contents of the application which are: Tutorials or quizzes. When the learner logs in to the system they will see the entry page as shown in Figure 12 and when clicking on tutorial section to access the learning material and the educational resource created or uploaded by the teacher or the parent they will be presented with list of the available learning materials as illustrated in Figure 13. 


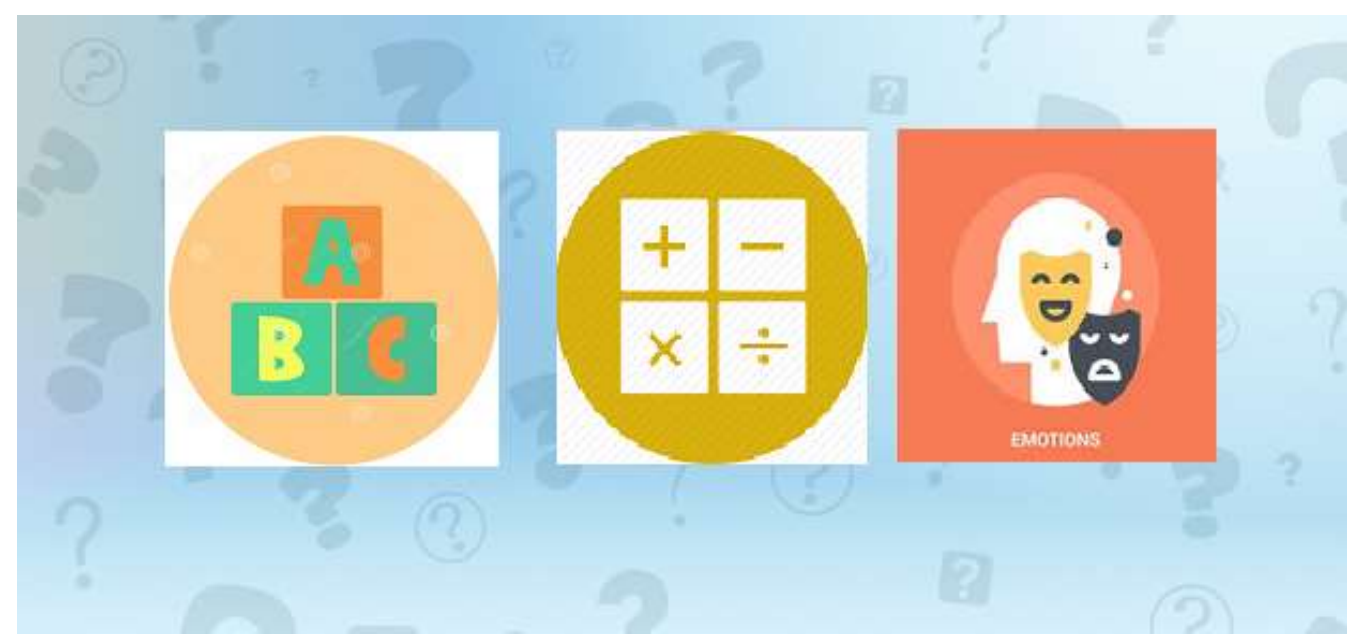

Figure 13: List of Available Tutorials in ACMLS Application

Figure 14 shows one of the tutorials available in the system and how the system posts to the learners

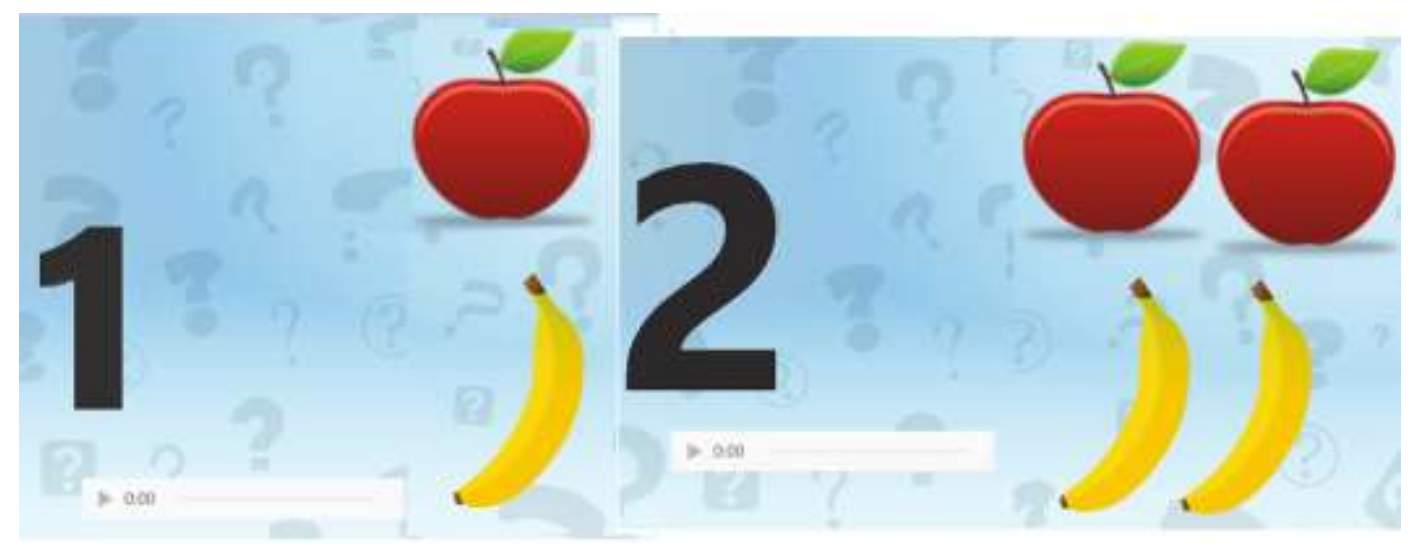

Figure 14: Numbers and Math Learning Interface 


\subsection{Test/Quizzes Page}

The quizzes page presented when the learner clicks on the quiz link. Each icon was a hypertext link, which the student could use to navigate between the available quizzes in the ACMLS application. Figure 15 shows available list of quizzes that the learner can do. And Figure 16 showing the entry page of the quiz which includes a 'Start' button to start the quiz, 'Options' button to change the timer settings for the quiz questions, 'Help' button to assist the student on how to use the system especially the quiz section as presented in Figure 17.

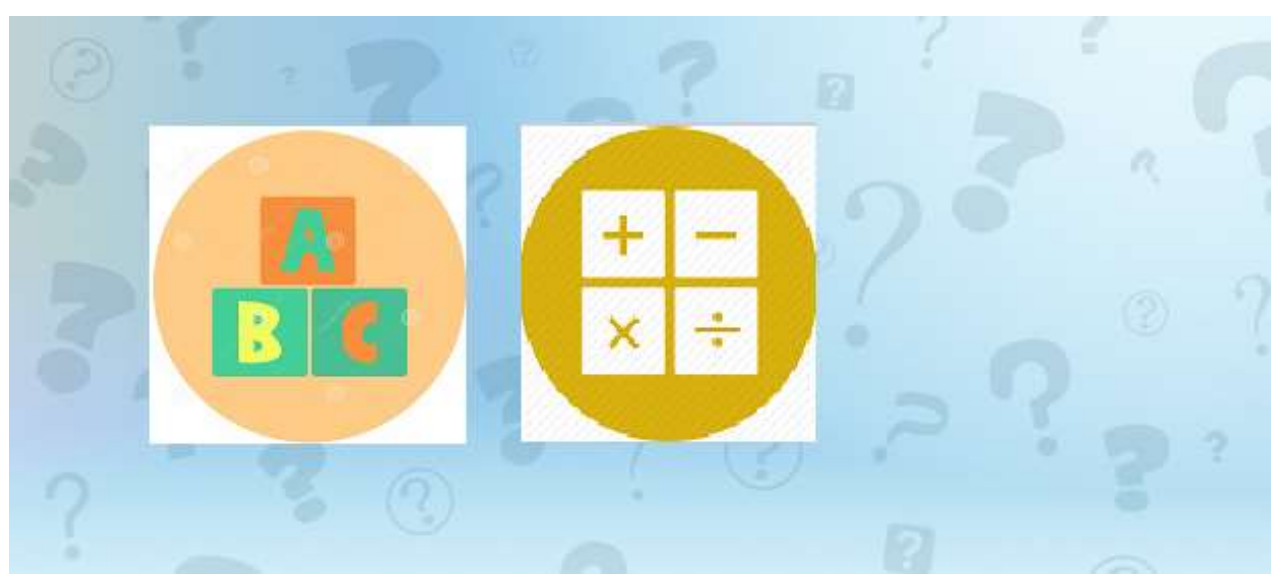

Figure 15: List of Available Quizzes in ACMLS Application 


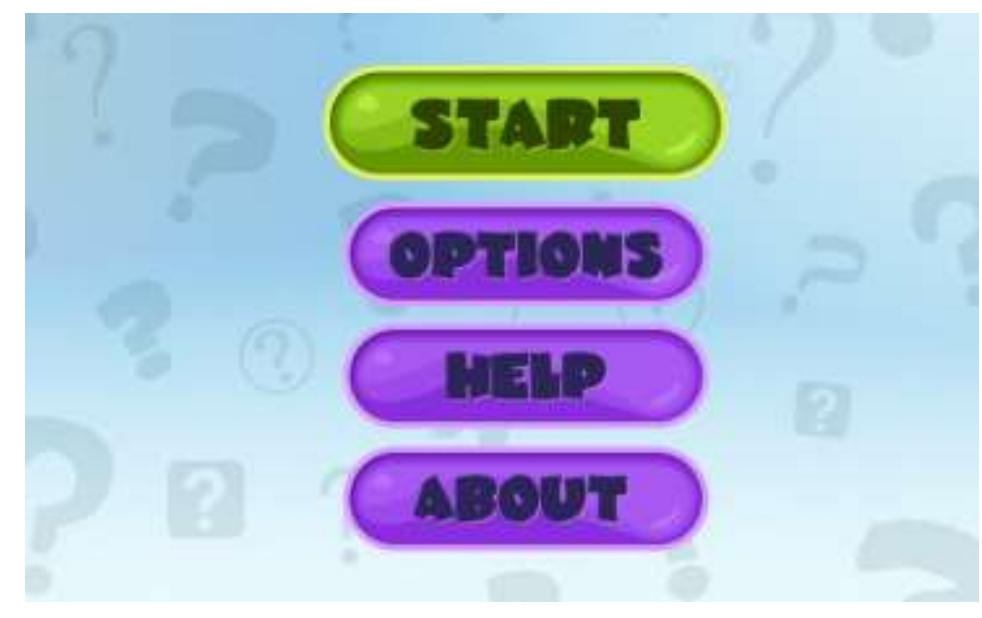

Figure 16: Quiz Entry Page Interface

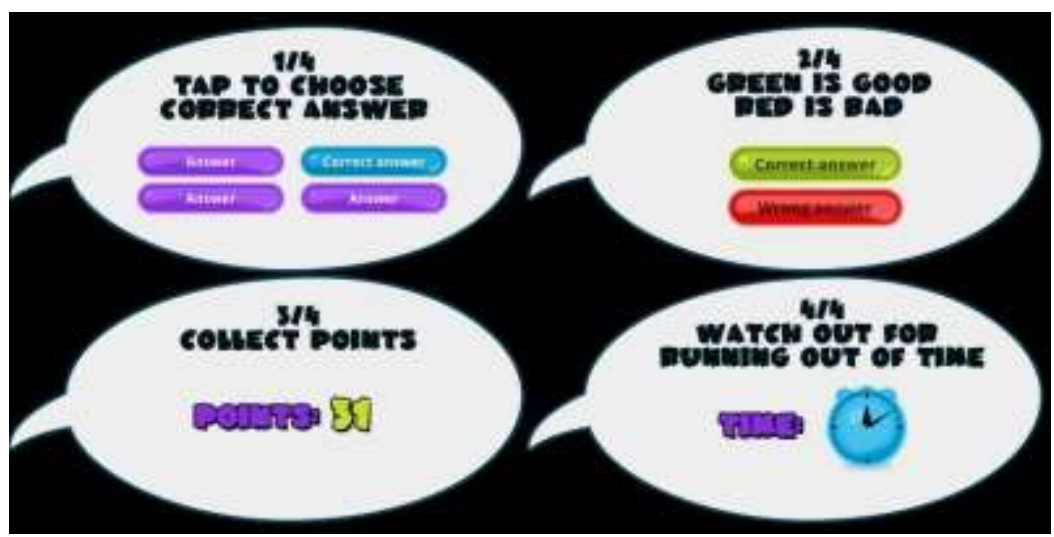

Figure 17: Help Page Interface

Figure 18 shows different types of quiz illustration using numerical/text or visualisation, in order to test the student's capability in different situations. The list of questions in the quiz section are uploaded by the teacher or the parent to test the learners after attending the tutorial session in the ACMLS application. 


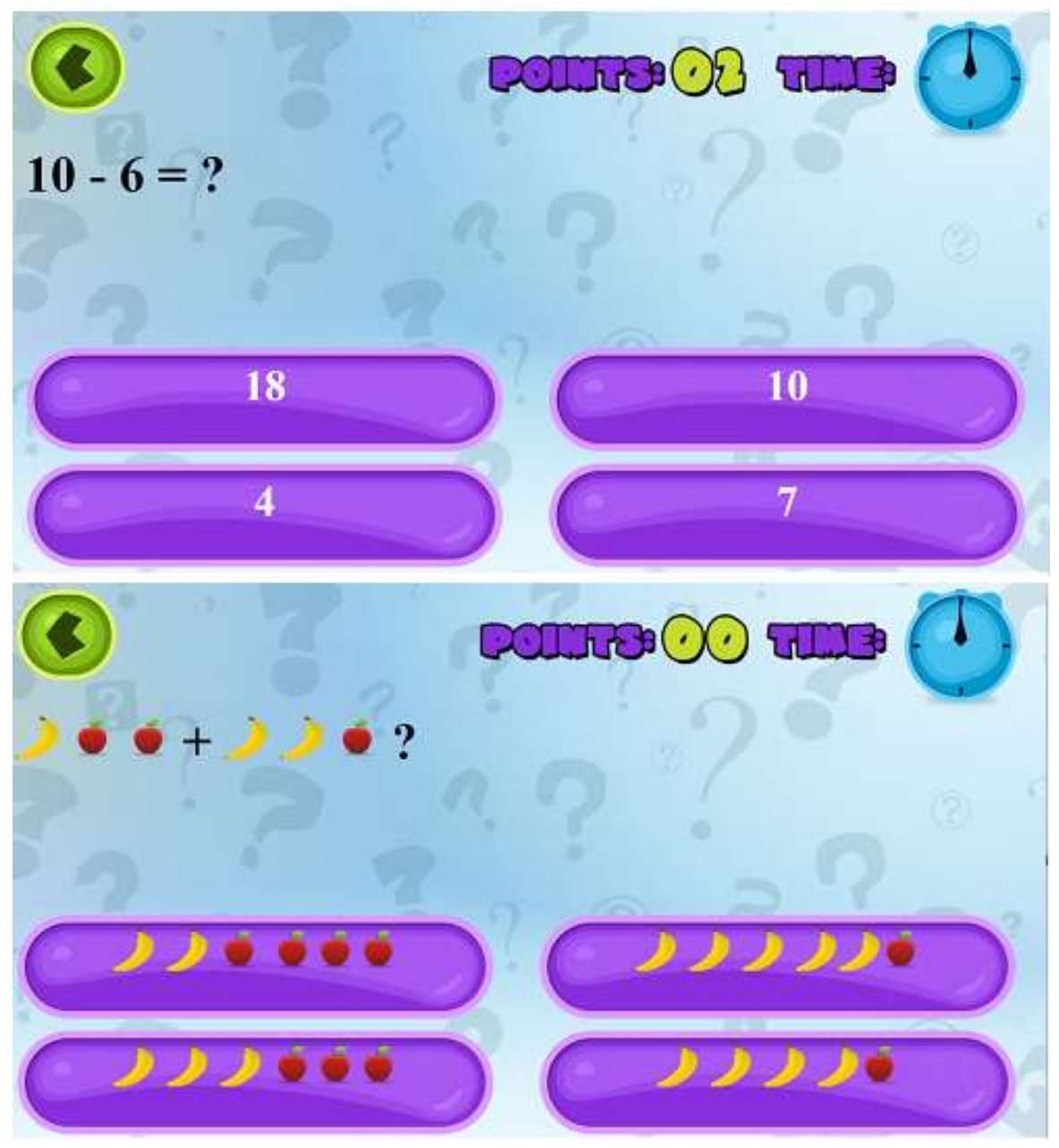

Figure 18: Different Quiz Presentation Interface

And Figure 19, shows the ACMLS system response to the correct answer and the wrong answer to a certain question. For example, when the student clicks on the correct answer the button will be blinking with a light blue colour and a feedback sound will be played in the background as well as a point will be added in the top right corner of the system and the timer will reset for the next question. However, the bottom Figure shows when the student click on the wrong answer, the feedback will be shown by highlighting the student answer in red colour and the correct answer in green as well as the feedback sound will be played in the system background and no points given for the wrong answer. 
At the end of the quiz the student will be given the score instantly. The system has the ability to allow the student to attend the quiz for a multiple times taking in considerations that autistic children are considered smart and they will memorize the correct answers location. Therefore, the system will shuffle the answers and distribute it in different location each time the student starts the quiz.

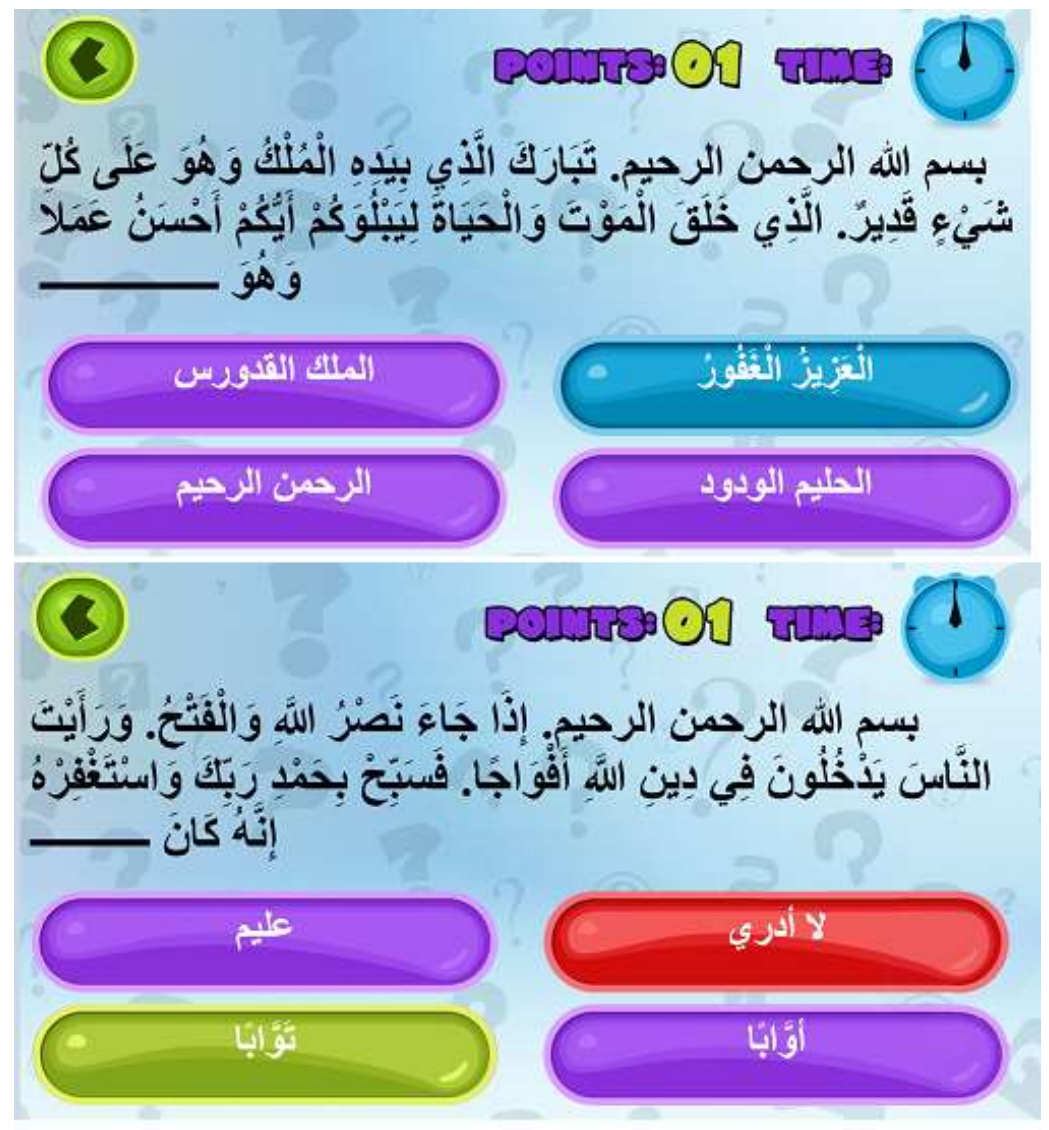

Figure 19: Quiz Interface and Answers Feedback

\subsection{Administration Section}

When the administrator logs in to the system, the entry page in Figure 20 will be loaded with two different navigational links; one for the students and the other is for the teachers/parent. The teachers/parent link is to allow administrator to add, modify and delete teacher or parent profile 
from the ACMLS application. And the learners' link is to add, modify and delete student information from the system.

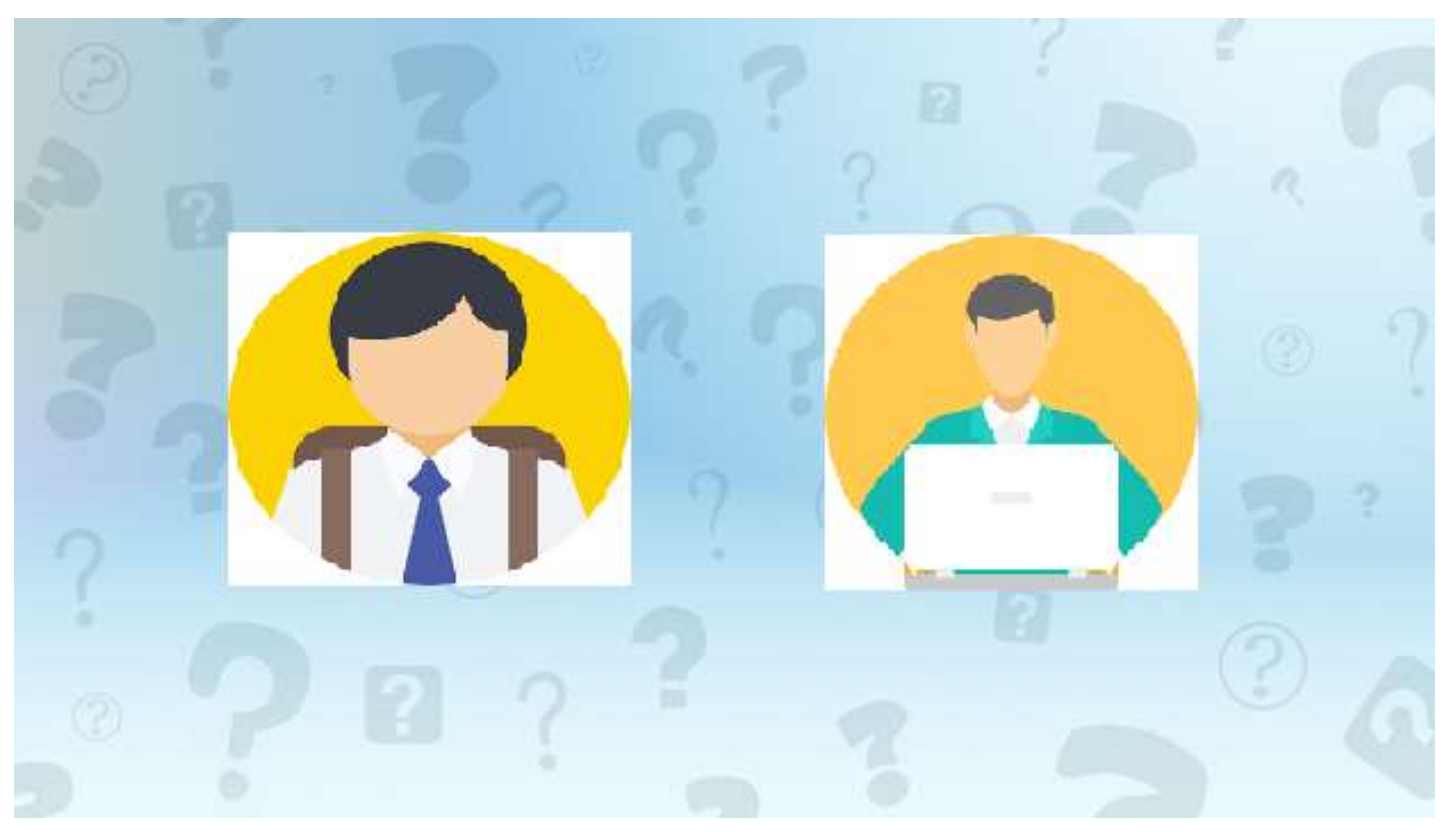

Figure 20: Administrator Home Page

Figure 21 explains the information needed to be filled up in order to sign up a new teacher or parent into the application. The same process is applied for enrolling new students into the system.

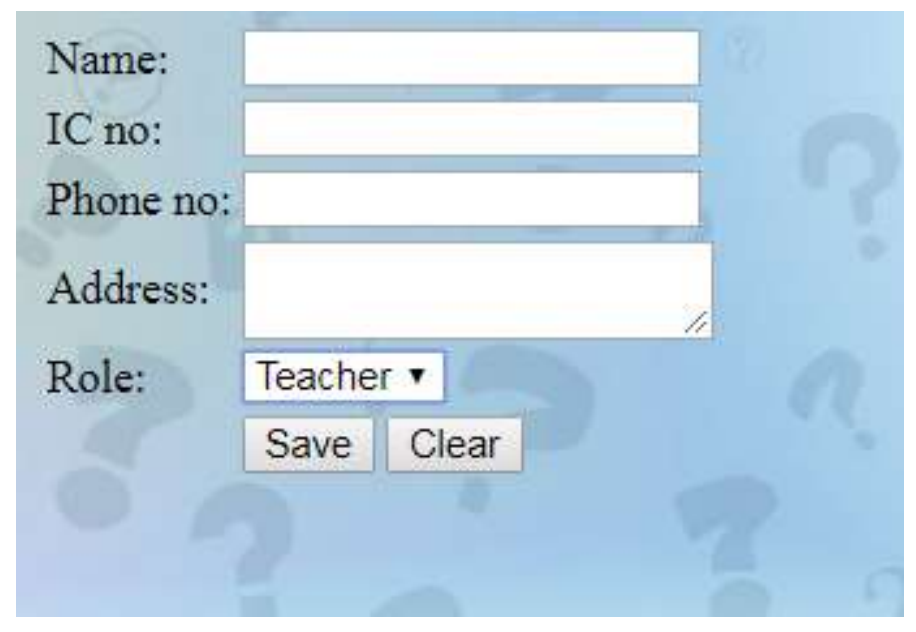

Figure 21: Administrator Adds New Teacher/Parent. 
Figure 22 presents list of students' statistics after taking numerous quizzes in ACMLS application, these data can present the learning progress for each student.

\begin{tabular}{|c|c|}
\hline Student A & (0) \\
\hline Choose the correct Answer (Math Quiz 1) & $20 / 25$ \\
\hline Choose the correct Answer (Math Quiz 1) & $17 / 25$ \\
\hline Choose the correct Answer (alphabet Quiz 2) & $10 / 15$ \\
\hline Choose the correct Answer (Math Quiz 1) & $21 / 25$ \\
\hline Student B & U \\
\hline Choose the correct Answer (Math Quiz 1) & $20 / 25$ \\
\hline Choose the correct Answer (alphabet Quiz 2) & $11 / 15$ \\
\hline Choose the correct Answer (alphabet Quiz 2) & $10 / 15$ \\
\hline Choose the correct Answer (alphabet Quiz 2) & $13 / 15$ \\
\hline Student $\mathrm{C}$ & \\
\hline Choose the correct Answer (Math Quiz 1) & $20 / 25$ \\
\hline Choose the correct Answer (alphabet Quiz 2) & $11 / 15$ \\
\hline 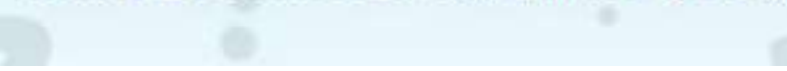 & 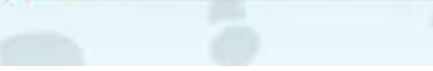 \\
\hline
\end{tabular}

\section{Figure 22: Students' Statistics}

\subsection{Teacher/Parent Section}

This page can be accessed by teachers or parent as long as they have access to the ACMLS application. Teachers can use the system to enrol new students to the ACMLS application as Figure 23 demonstrates. The student demographics should be filled up in the system as well as some personalization features which will be reflected on the student's profile such as: colour scheme, font size and style, the alert sound or tone and the feedback avatar. A huge advantage of personalized learning is the discovery of specific needs of a single user. Specifying these helps to reinforce abilities and tries to cover disabilities in ACMLS application. 


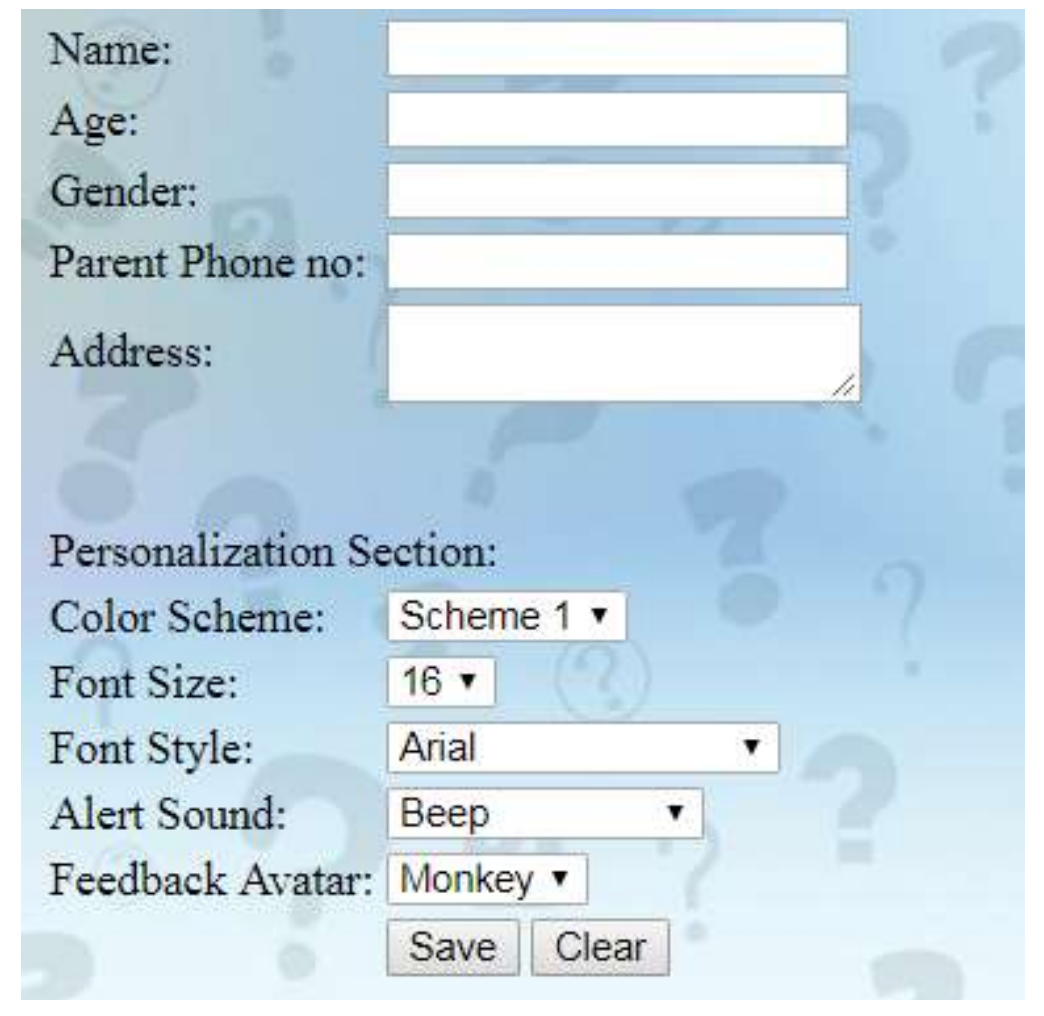

\section{Figure 23: Teacher Adds New Student}

Teacher or parent can create or upload a learning materials using the ACMLS application as shown in Figure 24 and Figure 25. there are two different ways to add new educational materials to the application; the first way is in text form where the text will be formatted and presented to the learners based on the personalized profile set up. And the second way is to upload a set of predesigned images to the application so that it will be presented to the learner as a slide show tutorials. The tutorial icon will be presented as a hyperlink image on the main tutorials page. 


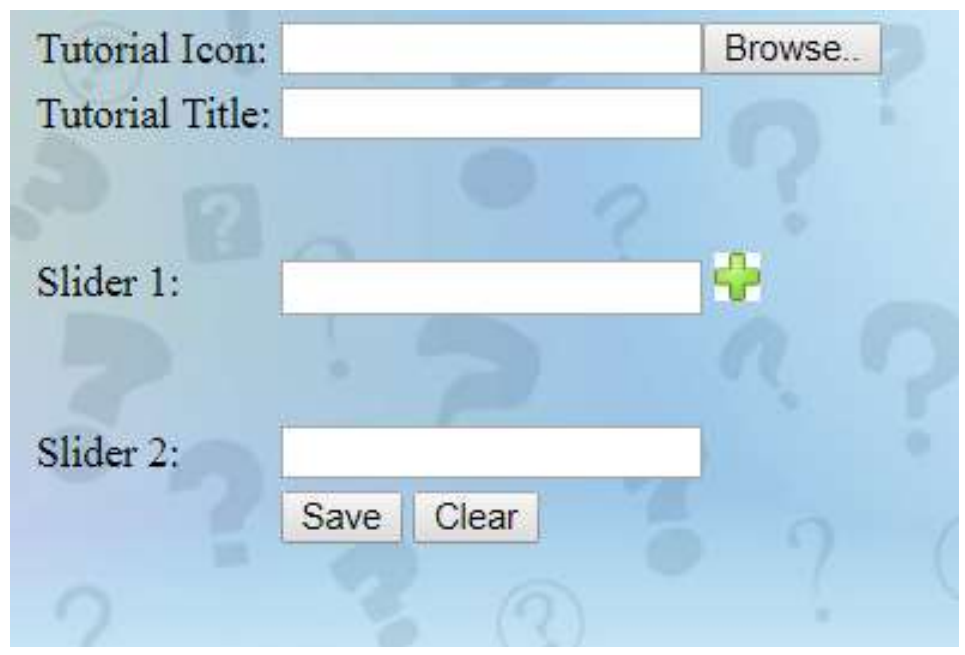

Figure 24: Adding New Tutorials to ACMLS Application (Text Form)

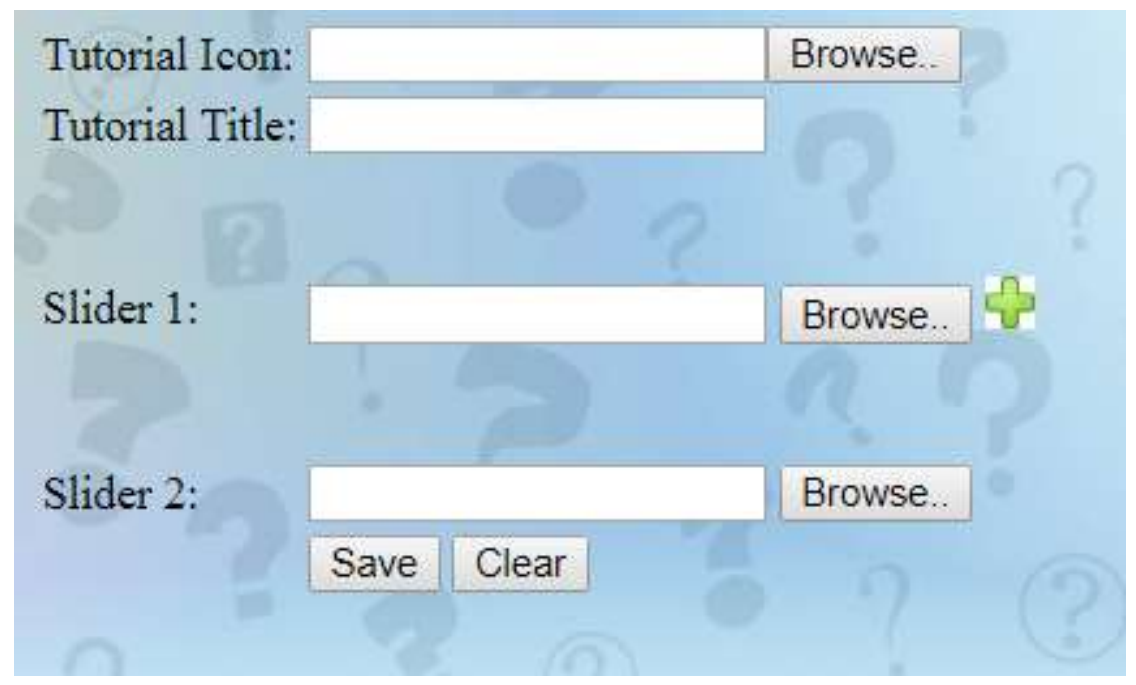

Figure 25: Adding New Tutorials to ACMLS Application (Images Form)

Figure 26 shows the process of adding new multiple choice quiz to the ACMLS application, it starts with adding a quiz icon which will be presented as a hyperlink image on the main page of the quiz section.

The teacher/parent can fill up the questions and the different answers as illustrated in Figure 26, the first answer (Answer 1 field) must be filled with correct answer. And the plus sign is to allow the user to add more questions to the quiz. 
The ACMLS application will shuffle these answers in every time the student launch the quiz so that students do not memorize the answers location.

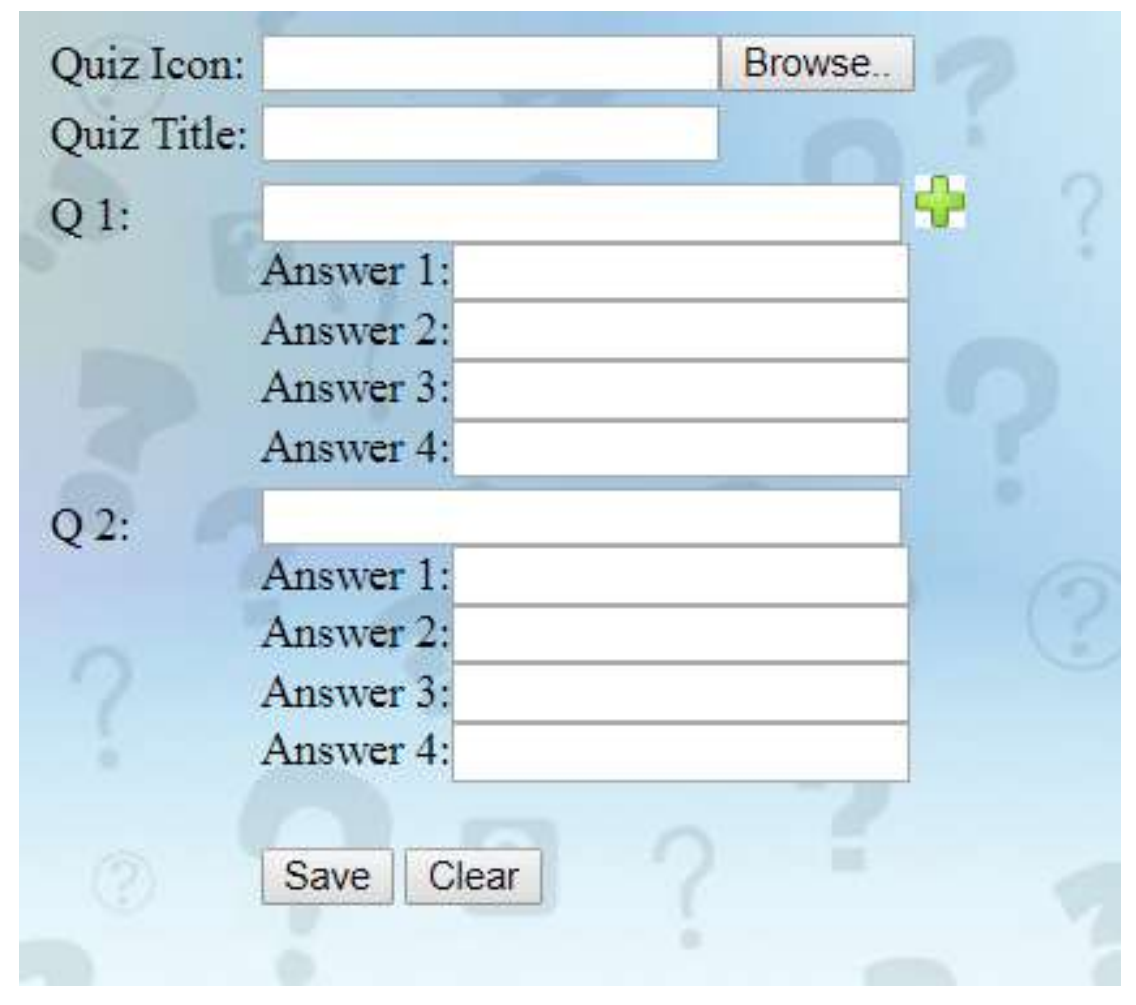

Figure 26: Adding New Quiz to ACMLS Application

\section{Conclusion}

This chapter introduced an overview about autism, causes and diagnostics tools or scales such as: childhood autism rating scale, autism diagnostics observation schedule, autism diagnostics interview-revised, autism behaviour checklist, Gilliam autism rating scale and autism treatment evaluation checklist. These scales are generally used to diagnose individuals with autism.

Children with autism are found to have impairments such as social, behavioural and communication impairments (Esposito \& Venuti, 2009; Tsai, 2012). This impairments in learning is caused as a result of inadequate sensory stimulation they get from the learning environment. 
As result of the impairments found in them, teaching these children has been challenging for teachers and parents (Busby, Ingram, Bowron, Oliver, \& Lyons, 2012).

Therefore, this chapter presented the proposed ACMLS model and its four components: education, design, participants and technology, each component was explained in details.

1. Participants' component was focused on the main participants (teachers, parents and children with autism) and role played for each one of them in ACMLS usage.

2. Technology component illustrated the tools used to develop the prototype and the use of HCI tools which will be incorporated into the ACMLS model in order to provide an interactive system for the system participants.

3. Design component explained the visual design of the educational materials provided to the end users for the purpose of learning taking in consideration the mental model of the children with autism.

4. Education component explained the styles, objectives and strategies as well as the methods i.e.: variability, repetition, motivation and visualization, which have to be implemented in the system to be able to make the system easy to use by the children with autism due to their skills impairments. The adaptive learning and cognitive models were considered for easy communication between children and the proposed system.

\section{Future Work}

Despite the evidence of the effectiveness and efficiency of the Adaptive Content Management Learning System (ACMLS) model to be used as a new medium for children with autism learning as a main achievement of this research. It's believed that improvements can be considered for further improvements and enhancements of the model. 
Improvement work on the ACMLS model is suggested as the following:

1. Incorporate Internet of Things (IoT) into the ACMLS model to combine smart environment into the model to assess children with autism abilities in multidisciplinary during learning.

2. Translate the ACMLS prototype to other languages and make it available for public use by parents of children with autism or teachers in autism schools.

3. Coordinated whole-brain neural network via ACMLS integrated smart devices.

4. Incorporate special physical activities for children with autism via a wearable devices which are integrated with the ACMLS model.

\section{References:}

Alessi, S. M., \& Trollip, S. R. (2001). Multimedia for learning: methods and development: Allyn \& Bacon, Incorporated.

Allen, R. B. (1997). Mental models and user models Handbook of human-computer interaction (pp. 49-63): Elsevier.

American Psychiatric Association. (1994). DSM-IV® Sourcebook (Vol. 1): American Psychiatric Pub.

American Psychiatric Association. (2000). Diagnostic and statistical manual of mental disorders (revised 4th ed.). Washington, DC: Author.

American Psychiatric Association. (2013). Diagnostic and statistical manual of mental disorders (DSM-5®): American Psychiatric Pub.

Attwood, T. (2004). Cognitive behaviour therapy for children and adults with Asperger's syndrome. Behaviour Change, 21(3), 147-161.

Autism Speaks. (2011). What is autism? Retrieved from https://www.autismspeaks.org/whatautism

Axelrod, S., McElrath, K. K., \& Wine, B. (2012). Applied behavior analysis: autism and beyond. Behavioral Interventions, 27(1), 1-15.

Baird, G., Simonoff, E., Pickles, A., Chandler, S., Loucas, T., Meldrum, D., \& Charman, T. (2006). Prevalence of disorders of the autism spectrum in a population cohort of children in South Thames: the Special Needs and Autism Project (SNAP). The lancet, 368(9531), 210-215.

Banire, B., Jomhari, N., \& Ahmad, R. (2015). Visual Hybrid Development Learning System (VHDLS) framework for children with autism. Journal of autism and developmental disorders, 45(10), 3069-3084.

Baron-Cohen, S. (2000). Theory of mind and autism: A review. International review of research in mental retardation, 23, 169-184.

Barry, M., \& Pitt, I. (2006). Interaction design: a multidimensional approach for learners with autism. Paper presented at the Proceedings of the 2006 conference on Interaction design and children. 
Barthélémy, C., Hameury, L., \& Lelord, G. (1995). La thérapie d'échange et de développement dans l'autisme de 1'enfant. Expansion Scientifique Française, Paris.

Battou, A. (2017). Designing an Adaptive Learning System Based on a Balanced Combination of Agile Learner Design and Learner Centered Approach. American Scientific Research Journal for Engineering, Technology, and Sciences (ASRJETS), 37(1), 178-186.

Bell, S. M., Cihak, D. F., \& Judge, S. (2010). A Preliminary Study: Do Alternative Certification Route Programs Develop the Necessary Skills and Knowledge in Assistive Technology? International Journal of Special Education, 25(3), 110-118.

Bölte, S., Golan, O., Goodwin, M. S., \& Zwaigenbaum, L. (2010). What can innovative technologies do for autism spectrum disorders? autism, 14(3), 155-159.

Bondy, A., \& Frost, L. (2002). A Picture's Worth: PECS and Other Visual Communication Strategies in Autism. Topics in Autism: ERIC.

Bouck, E. C., Meyer, N. K., Joshi, G. S., \& Schleppenbach, D. (2013). Accessing algebra via MathSpeak ${ }^{\mathrm{TM}}$ : Understanding the potential and pitfalls for students with visual impairments. Journal of Special Education Technology, 28(1), 49-63.

Brewer, N., Young, R. L., \& Barnett, E. (2017). Measuring theory of mind in adults with autism spectrum disorder. Journal of autism and developmental disorders, 47(7), 1927-1941.

Brown, H. K., Ouellette-Kuntz, H., Hunter, D., Kelley, E., Cobigo, V., \& Lam, M. (2011). Beyond an autism diagnosis: children's functional independence and parents' unmet needs. Journal of autism and developmental disorders, 41(10), 1291-1302.

Bryant, B. R., Seok, S., Ok, M., \& Bryant, D. P. (2012). Individuals with intellectual and/or developmental disabilities use of assistive technology devices in support provision. Journal of Special Education Technology, 27(2), 41-57.

Busby, R., Ingram, R., Bowron, R., Oliver, J., \& Lyons, B. (2012). Teaching elementary children with autism: Addressing teacher challenges and preparation needs. The Rural Educator, $33(2)$.

Charman, T. (2002). The prevalence of autism spectrum disorders. European child \& adolescent psychiatry, 11(6), 249-256.

Chen, Q., \& Sharma, V. (2002). Human factors in interface design: an analytical survey and perspective Human factors in information systems (pp. 45-54): IGI Global.

Coleman, M. B. (2011). Successful Implementation of Assistive Technology to Promote Access to Curriculum and Instruction for Students with Physical Disabilities. Physical Disabilities: Education and Related Services, 30(2), 2-22.

Coleman, M. B., MacLauchlan, M. P., Cihak, D. F., Martin, M. S., \& Wolbers, K. (2015). Comparing Teacher-Provided and Computer-Assisted Simultaneous Prompting for Vocabulary Development With Students Who Are Deaf or Hard of Hearing. Journal of Special Education Technology, 30(3), 145-156.

Corsello, C. M. (2005). Early intervention in autism. Infants \& Young Children, 18(2), 74-85.

Cox, R. D., \& Schopler, E. (1993). Aggression and self-injurious behaviors in persons with autism: The TEACCH approach. Acta Paedopsychiatrica: International Journal of Child \& Adolescent Psychiatry.

Cumley, G., Maro, J., \& Stanek, M. (2009). Assistive technology for communication. Assessing students need for assistive technology.

Davis, M., Dautenhahn, K., Powell, S., \& Nehaniv, C. (2010). Guidelines for researchers and practitioners designing software and software trials for children with autism. Journal of Assistive Technologies, 4(1), 38-48. 
Davis, S. E. (2007). Learning styles and memory. Institute for Learning Styles Journal, 1(1), 4651.

Devine, D. P. (2014). Self-injurious behaviour in autistic children: a neuro-developmental theory of social and environmental isolation. Psychopharmacology, 231(6), 979-997.

Douglas, K. H., Wojcik, B. W., \& Thompson, J. R. (2012). Is there an app for that? Journal of Special Education Technology, 27(2), 59-70.

Doyle, T., \& Arnedillo-Sánchez, I. (2011). Using multimedia to reveal the hidden code of everyday behaviour to children with autistic spectrum disorders (ASDs). Computers \& Education, 56(2), 357-369.

Epstein, J., \& Klinkenberg, W. D. (2002). Collecting data via the Internet: The development and deployment of a web-based survey. Journal of Technology in Human Services, 19(2-3), 33-47.

Esposito, G., \& Venuti, P. (2009). Symmetry in infancy: analysis of motor development in autism spectrum disorders. Symmetry, 1(2), 215-225.

Evans, J. R., \& Mathur, A. (2005). The value of online surveys. Internet research, 15(2), 195-219.

Faulkner, C., \& Faulkner, C. (1998). The essence of human-computer interaction: Prentice Hall London.

Felder, R. M., \& Brent, R. (2005). Understanding student differences. Journal of engineering education, 94(1), 57-72.

Ferreira, M. I. J., Travassos, X. L., Sampaio, R., \& Pereira-Guizzo, C. d. S. (2013). Digital Games and Assistive Technology: Improvement of Communication of Children with Cerebral Palsy. International Journal of Special Education, 28(2), 36-46.

Fricker, R. D., \& Schonlau, M. (2002). Advantages and disadvantages of Internet research surveys: Evidence from the literature. Field methods, 14(4), 347-367.

Ganz, J. B., Simpson, R. L., \& Lund, E. M. (2012). The picture exchange communication system (PECS): A promising method for improving communication skills of learners with autism spectrum disorders. Education and training in autism and developmental disabilities, 176186.

Gelbar, N. W., Smith, I., \& Reichow, B. (2014). Systematic review of articles describing experience and supports of individuals with autism enrolled in college and university programs. Journal of autism and developmental disorders, 44(10), 2593-2601.

Gierach, J. (2009). Assessing students' needs for assistive technology (ASNAT). Milton, WI: Wisconsin Assistive Technology Initiative.

Gillham, M., \& Buckner, K. (1997). User Evaluation of Hypermedia Encyclopedias. Journal of Educational Multimedia and Hypermedia, 6(1), 77-90.

Golan, O., Ashwin, E., Granader, Y., McClintock, S., Day, K., Leggett, V., \& Baron-Cohen, S. (2010). Enhancing emotion recognition in children with autism spectrum conditions: An intervention using animated vehicles with real emotional faces. Journal of autism and developmental disorders, 40(3), 269-279.

Goldsmith, T. R., \& LeBlanc, L. A. (2004). Use of technology in interventions for children with autism. Journal of Early and Intensive Behavior Intervention, 1(2), 166.

Gonzalez, C., Martin, J. M., Minshew, N. J., \& Behrmann, M. (2013). Practice makes improvement: How adults with autism out-perform others in a naturalistic visual search task. Journal of autism and developmental disorders, 43(10), 2259-2268. 
Goodwin, M. S. (2008). Enhancing and accelerating the pace of autism research and treatment: The promise of developing innovative technology. Focus on Autism and Other Developmental Disabilities, 23(2), 125-128.

Gosling, S. D., Vazire, S., Srivastava, S., \& John, O. P. (2004). Should we trust web-based studies? A comparative analysis of six preconceptions about internet questionnaires. American Psychologist, 59(2), 93.

Gray, C. A., \& Garand, J. D. (1993). Social stories: Improving responses of students with autism with accurate social information. Focus on autistic behavior, 8(1), 1-10.

Greenspan, S. I., \& Wieder, S. (1999). A functional developmental approach to autism spectrum disorders. Journal of the Association for Persons with Severe Handicaps, 24(3), 147-161.

Grynszpan, O., Martin, J.-C., \& Nadel, J. (2008). Multimedia interfaces for users with high functioning autism: An empirical investigation. International Journal of Human-Computer Studies, 66(8), 628-639.

Harris, S. L., \& Handleman, J. S. (2000). Age and IQ at intake as predictors of placement for young children with autism: A four-to six-year follow-up. Journal of autism and developmental disorders, 30(2), 137-142.

Hegarty, M. (2004). Dynamic visualizations and learning: Getting to the difficult questions. Learning and Instruction, 14(3), 343-351.

Hersh, M. A., \& Johnson, M. A. (2008). Disability and assistive technology systems. Assistive technology for visually impaired and blind people, 1-50.

Higgins, K., \& Boone, R. (1996). Creating individualized computer-assisted instruction for students with autism using multimedia authoring software. Focus on Autism and Other Developmental Disabilities, 11(2), 69-78.

Hine, J. F., \& Wolery, M. (2006). Using point-of-view video modeling to teach play to preschoolers with autism. Topics in Early Childhood Special Education, 26(2), 83-93.

Horton, W. K. (1990). Designing and writing online documentation: help files to hypertext: John Wiley \& Sons, Inc.

Howlin, P. (1998). Practitioner review: psychological and educational treatments for autism. Journal of Child Psychology and Psychiatry, 39(3), 307-322.

Hulusic, V., \& Pistoljevic, N. (2012). "LeFCA": Learning framework for children with autism. Procedia Computer Science, 15, 4-16.

Ibrahim, S., AlSharabi, K., Djemal, R., \& Alsuwailem, A. (2016). An adaptive learning approach for EEG-based computer aided diagnosis of epilepsy. Paper presented at the Intelligent Technology and Its Applications (ISITIA), 2016 International Seminar on.

Kaldy, Z., Kraper, C., Carter, A. S., \& Blaser, E. (2011). Toddlers with autism spectrum disorder are more successful at visual search than typically developing toddlers. Developmental science, 14(5), 980-988.

Kerns, D. (2013). Six key benefits of adaptive learning. Retrieved from http://www.dreambox.com/blog/six-benefits-of-adaptive-learning

Khurana, R. (2001). Html 4 U: APH Publishing Corporations.

Kishida, Y., \& Kemp, C. (2006). A measure of engagement for children with intellectual disabilities in early childhood settings: A preliminary study. Journal of Intellectual and Developmental Disability, 31(2), 101-114.

Konstantinidis, E. I., Luneski, A., Frantzidis, C. A., Costas, P., \& Bamidis, P. D. (2009). A proposed framework of an interactive semi-virtual environment for enhanced education of 
children with autism spectrum disorders. Paper presented at the computer-based medical systems, 2009. CBMS 2009. 22nd IEEE international symposium on.

Lancioni, G., Singh, N., O'reilly, M., Oliva, D., \& Basili, G. (2005). An overview of research on increasing indices of happiness of people with severe/profound intellectual and multiple disabilities. Disability and rehabilitation, 27(3), 83-93.

Lancioni, G. E., Bellini, D., Oliva, D., Singh, N. N., O’Reilly, M. F., \& Sigafoos, J. (2010). Camera-based microswitch technology for eyelid and mouth responses of persons with profound multiple disabilities: Two case studies. Research in developmental disabilities, 31(6), 1509-1514.

Lancioni, G. E., O’Reilly, M. F., Singh, N. N., Sigafoos, J., Didden, R., Oliva, D., . . Groeneweg, J. (2009). Persons with multiple disabilities accessing stimulation and requesting social contact via microswitch and VOCA devices: New research evaluation and social validation. Research in developmental disabilities, 30(5), 1084-1094.

Lancioni, G. E., Singh, N. N., O’Reilly, M. F., Sigafoos, J., Oliva, D., Scalini, L., . . Di Bari, M. (2007). Promoting foot-leg movements in children with multiple disabilities through the use of support devices and technology for regulating contingent stimulation. Cognitive processing, 8(4), 279-283.

Lang, R., Ramdoss, S., Raulston, T., Carnet, A., Sigafoos, J., Didden, R., . . O’Reilly, M. F. (2014). Assistive technology for people with autism spectrum disorders Assistive Technologies for People with Diverse Abilities (pp. 157-190): Springer.

Lavie, N. (2010). Attention, distraction, and cognitive control under load. Current Directions in Psychological Science, 19(3), 143-148.

Leach, C. (2010). The use of Smartboards and bespoke software to develop and deliver an inclusive, individual and interactive learning curriculum for students with ASD. Journal of Assistive Technologies, 4(1), 54-57.

Lee, G. K., \& Carter, E. W. (2012). Preparing Transition-Age Students with High-Functioning Autism Spectrum Disorders for Meaningful Work. Psychology in the Schools, 49(10), 9881000 .

Lovaas, O. I. (1979). Contrasting illness and behavioral models for the treatment of autistic children: a historical perspective. Journal of autism and developmental disorders, 9(4), 315-323.

Lovaas, O. I., Ackerman, A., Alexander, D., Firestone, P., Perkins, J., \& Young, D. (1981). Teaching developmentally disabled children: The me book: Pro-ed Austin, TX.

Matson, J. L., \& Boisjoli, J. A. (2008). Strategies for assessing Asperger's syndrome: A critical review of data based methods. Research in autism spectrum disorders, 2(2), 237-248.

Matson, J. L., \& Goldin, R. L. (2013). Comorbidity and autism: trends, topics and future directions. Research in autism spectrum disorders, 7(10), 1228-1233.

Matson, J. L., \& Jang, J. (2014). Treating aggression in persons with autism spectrum disorders: A review. Research in developmental disabilities, 35(12), 3386-3391.

Matson, J. L., \& Smith, K. R. (2008). Current status of intensive behavioral interventions for young children with autism and PDD-NOS. Research in autism spectrum disorders, 2(1), 60-74.

Mayer, R. E. (2005). The Cambridge handbook of multimedia learning: Cambridge university press.

McCoy, K., \& Hermansen, E. (2007). Video modeling for individuals with autism: A review of model types and effects. Education and treatment of children, 183-213. 
McCulloch, G. (2004). Documentary research: In education, history and the social sciences: Routledge.

McWilliam, R., \& Bailey Jr, D. B. (1995). Effects of classroom social structure and disability on engagement. Topics in Early Childhood Special Education, 15(2), 123-147.

Mesibov, G., Thomas, J. B., Chapman, S., \& Schopler, E. (2007). TEACCH Transition Assessment Profile: TTAP: Pro-ed Austin, TX.

Mesibov, G. B., \& Shea, V. (2010). The TEACCH program in the era of evidence-based practice. Journal of autism and developmental disorders, 40(5), 570-579.

Mesibov, G. B., Shea, V., \& Schopler, E. (2005). The TEACCH approach to autism spectrum disorders: Springer Science \& Business Media.

Michaud, F., Duquette, A., \& Nadeau, I. (2003). Characteristics of mobile robotic toys for children with pervasive developmental disorders. Paper presented at the Systems, Man and Cybernetics, 2003. IEEE International Conference on.

Millwood, R., \& Stevens, M. (1990). What is the modelling curriculum? Computer Assisted Learning (pp. 249-254): Elsevier.

Mitchell, P., Parsons, S., \& Leonard, A. (2007). Using virtual environments for teaching social understanding to 6 adolescents with autistic spectrum disorders. Journal of autism and developmental disorders, 37(3), 589-600.

Moody, A. K. (2012). Family Connections: Visual Supports for Promoting Social Skills in Young Children: A Family Perspective: Carol McNulty, Editor. Childhood Education, 88(3), 191194.

Moore, D. W., Anderson, A., Treccase, F., Deppeler, J., Furlonger, B., \& Didden, R. (2013). A video-based package to teach a child with autism spectrum disorder to write her name. Journal of Developmental and Physical Disabilities, 25(5), 493-503.

Morrison, G. R., Ross, S. M., Kemp, J. E., \& Kalman, H. (2010). Designing effective instruction: John Wiley \& Sons.

National Research Council. (2001). Educating children with autism: National Academies Press.

Nielsen, J., \& Nielsen, B. (1995). Multimedia and hypertext: The Internet and beyond: Morgan Kaufmann.

Norgate, R. (1998). Reducing self injurious behaviour in a child with severe learning difficulties: enhancing predictability and structure. Educational Psychology in Practice, 14(3), 176182.

Norman, D. A. (2014). Some observations on mental models Mental models (pp. 15-22): Psychology Press.

Ostryn, C., Wolfe, P. S., \& Rusch, F. R. (2008). A review and analysis of the picture exchange communication system (PECS) for individuals with autism spectrum disorders using a paradigm of communication competence. Research and Practice for Persons with Severe Disabilities, 33(1-2), 13-24.

Ozonoff, S., \& Cathcart, K. (1998). Effectiveness of a home program intervention for young children with autism. Journal of autism and developmental disorders, 28(1), 25-32.

Ozonoff, S., \& Miller, J. N. (1995). Teaching theory of mind: A new approach to social skills training for individuals with autism. Journal of autism and developmental disorders, 25(4), 415-433.

Pajareya, K., \& Nopmaneejumruslers, K. (2012). A one-year prospective follow-up study of a DIR/Floortime ${ }^{\mathrm{TM}}$ parent training intervention for preschool children with autistic spectrum disorders. Journal of the Medical Association of Thailand, 95(9), 1184. 
Panerai, S., Ferrante, L., \& Caputo, V. (1997). The TEACCH strategy in mentally retarded children with autism. Journal of autism and developmental disorders, 27(3), 345-347.

Panerai, S., Ferrante, L., Caputo, V., \& Impellizzeri, C. (1998). Use of structured teaching for treatment of children with autism and severe and profound mental retardation. Education and Training in Mental Retardation and Developmental Disabilities, 367-374.

Panerai, S., Ferrante, L., \& Zingale, M. (2002). Benefits of the Treatment and Education of Autistic and Communication Handicapped Children (TEACCH) programme as compared with a non-specific approach. Journal of intellectual disability research, 46(4), 318-327.

Panerai, S., Zingale, M., Trubia, G., Finocchiaro, M., Zuccarello, R., Ferri, R., \& Elia, M. (2009). Special education versus inclusive education: the role of the TEACCH program. Journal of autism and developmental disorders, 39(6), 874-882.

Panyan, M. V. (1984). Computer technology for autistic students. Journal of autism and developmental disorders, 14(4), 375-382.

Parsons, S., Beardon, L., Neale, H., Reynard, G., Eastgate, R., Wilson, J., . . Hopkins, E. (2000). Development of social skills amongst adults with Asperger's Syndrome using virtual environments: the 'AS Interactive'project. Paper presented at the Proc. The 3rd International Conference on Disability, Virtual Reality and Associated Technologies, ICDVRAT.

Patel, V. L., Yoskowitz, N. A., Arocha, J. F., \& Shortliffe, E. H. (2009). Cognitive and learning sciences in biomedical and health instructional design: A review with lessons for biomedical informatics education. Journal of biomedical informatics, 42(1), 176-197.

Pennington, R. C. (2010). Computer-assisted instruction for teaching academic skills to students with autism spectrum disorders: A review of literature. Focus on Autism and Other Developmental Disabilities, 25(4), 239-248.

Peters-Scheffer, N., Didden, R., Korzilius, H., \& Sturmey, P. (2011). A meta-analytic study on the effectiveness of comprehensive ABA-based early intervention programs for children with autism spectrum disorders. Research in autism spectrum disorders, 5(1), 60-69.

Pinder-Amaker, S. (2014). Identifying the unmet needs of college students on the autism spectrum. Harvard Review of Psychiatry, 22(2), 125-137.

Piper, A. M., O'Brien, E., Morris, M. R., \& Winograd, T. (2006). SIDES: a cooperative tabletop computer game for social skills development. Paper presented at the Proceedings of the 2006 20th anniversary conference on Computer supported cooperative work.

Preece, J., \& Rombach, H. D. (1994). A taxonomy for combining software engineering and humancomputer interaction measurement approaches: towards a common framework. International Journal of Human-Computer Studies, 41(4), 553-583.

Pring, R. (2000). The 'false dualism' of educational research. Journal of Philosophy of Education, 34(2), 247-260.

Prizant, B. M., Wetherby, A. M., Rubin, E., \& Laurent, A. C. (2003). The SCERTS Model: A transactional, family-centered approach to enhancing communication and socioemotional abilities of children with autism spectrum disorder. Infants \& Young Children, 16(4), 296316.

Putnam, C., \& Chong, L. (2008). Software and technologies designed for people with autism: what do users want? Paper presented at the Proceedings of the 10th international ACM SIGACCESS conference on Computers and accessibility.

Quill, K. A. (1997). Instructional considerations for young children with autism: The rationale for visually cued instruction. Journal of autism and developmental disorders, 27(6), 697-714. 
Rada, R., \& Diaper, D. (1991). Converting text to hypertext and vice versa. Hypermedia/Hypertext and object-oriented databases, 167-200.

Rajendran, G., \& Mitchell, P. (2000). Computer mediated interaction in Asperger's syndrome: The Bubble Dialogue program. Computers \& Education, 35(3), 189-207.

Reed, M. J., Kennett, D. J., Lewis, T., Lund-Lucas, E., Stallberg, C., \& Newbold, I. L. (2009). The relative effects of university success courses and individualized interventions for students with learning disabilities. Higher Education Research \& Development, 28(4), 385-400.

Reed, P., \& Lahm, E. (2004). Assessing students' needs for assistive technology: A resource manual for school district teams. Oshkosh: WI: Wisconsin Assistive

Reed, P. R., \& Bowser, G. (2013). Assistive technology pointers for parents: Wisconsin Assistive Technology Initiative.

Reed, P. R., \& Lahm, E. A. (2007). A resource guide for teachers and administrators about assistive technology. Wisconsin, WI: Wisconsin Assistive Technology Initiative.

Reichow, B. (2012). Overview of meta-analyses on early intensive behavioral intervention for young children with autism spectrum disorders. Journal of autism and developmental disorders, 42(4), 512-520.

Remington, B., Hastings, R. P., Kovshoff, H., Degli Espinosa, F., Jahr, E., Brown, T., . . . MacLean, J., William E. (2007). Early intensive behavioral intervention: outcomes for children with autism and their parents after two years. American Journal on Mental Retardation, 112(6), 418-438.

Robson, C., Blampied, N., \& Walker, L. (2015). Effects of feedforward video self-modelling on reading fluency and comprehension. Behaviour Change, 32(1), 46-58.

Rodríguez, W. R., Saz, O., Lleida, E., Vaquero, C., \& Escartín, A. (2008). COMUNICA-tools for speech and language therapy. Paper presented at the WOCCI.

Rogers, S., Hall, T., Osaki, D., Reaven, J., \& Herbison, J. (2000). The Denver Model: A comprehensive, integrated educational approach to young children with autism and their families. Preschool education programs for children with autism, 95-135.

Rogers, S. J. (1998). Empirically supported comprehensive treatments for young children with autism. Journal of clinical child psychology, 27(2), 168-179.

Ruble, L. A., \& McGrew, J. H. (2007). Community services outcomes for families and children with autism spectrum disorders. Research in autism spectrum disorders, 1(4), 360-372.

Schopler, E. (1994). A statewide program for the treatment and education of autistic and related communication handicapped children (TEACCH). Psychoses and Pervasive Developmental Disorders, 3(7), 91-103.

Schopler, E., Mesibov, G. B., \& Hearsey, K. (1995). Structured teaching in the TEACCH system Learning and cognition in autism (pp. 243-268): Springer.

Schopler, E., \& Reichler, R. J. (1971). Parents as cotherapists in the treatment of psychotic children. Journal of autism and developmental disorders, 1(1), 87-102.

Sigafoos, J., O’Reilly, M., Cannella, H., Edrisinha, C., de la Cruz, B., Upadhyaya, M., ... Garver, C. (2007). Evaluation of a video prompting and fading procedure for teaching dish washing skills to adults with developmental disabilities. Journal of Behavioral Education, 16(2), 93-109.

Stahmer, A. C., Akshoomoff, N., \& Cunningham, A. B. (2011). Inclusion for toddlers with autism spectrum disorders: The first ten years of a community program. autism, 15(5), 625-641. 
Stasolla, F., Boccasini, A., Perilli, V., Damiani, R., \& Albano, V. (2015). Assistive Technology for Promoting Adaptive Skills of Children with Autism Spectrum Disorders: A Literature Overview. Int J Psychol Psychoanal, 1(008).

Tanaka, J. W., Wolf, J. M., Klaiman, C., Koenig, K., Cockburn, J., Herlihy, L., . . Schultz, R. T. (2010). Using computerized games to teach face recognition skills to children with autism spectrum disorder: the Let's Face It! program. Journal of Child Psychology and Psychiatry, 51(8), 944-952.

Tetreault, A. S., \& Lerman, D. C. (2010). Teaching social skills to children with autism using point-of-view video modeling. Education and treatment of children, 33(3), 395-419.

Tincani, M. (2004). Comparing the picture exchange communication system and sign language training for children with autism. Focus on Autism and Other Developmental Disabilities, 19(3), 152-163.

Tjus, T., Heimann, M., \& Nelson, K. E. (2001). Interaction patterns between children and their teachers when using a specific multimedia and communication strategy: observations from children with autism and mixed intellectual disabilities. autism, 5(2), 175-187.

Tsai, L. Y. (2012). Sensitivity and specificity: DSM-IV versus DSM-5 criteria for autism spectrum disorder. Am J Psychiatry, 169(10), 1009-1011. doi:10.1176/appi.ajp.2012.12070922

Tsang, S. K., Shek, D. T., Lam, L. L., Tang, F. L., \& Cheung, P. M. (2007). Brief Report: Application of the TEACCH Program on Chinese Pre-School Children with AutismDoes Culture Make a Difference? Journal of autism and developmental disorders, 37(2), 390-396.

Tzanakaki, P., Grindle, C., Hastings, R. P., Hughes, J. C., Kovshoff, H., \& Remington, B. (2012). How and why do parents choose Early Intensive Behavioral Intervention for their young child with Autism? Education and training in autism and developmental disabilities, 5871.

Umbach, P. D. (2004). Web surveys: Best practices. New directions for institutional research, 2004(121), 23-38.

Van der Meer, L., Achmadi, D., Cooijmans, M., Didden, R., Lancioni, G. E., O’Reilly, M. F., .. . Hodis, F. (2015). An iPad-based intervention for teaching picture and word matching to a student with ASD and severe communication impairment. Journal of Developmental and Physical Disabilities, 27(1), 67-78.

Van Rijn, H., \& Stappers, P. J. (2008). The puzzling life of autistic toddlers: design guidelines from the LINKX project. Advances in Human-Computer Interaction, 2008.

Vora, P. R., \& Helander, M. G. (1997). Hypertext and its implications for the Internet Handbook of Human-Computer Interaction (Second Edition) (pp. 877-914): Elsevier.

Watkins, N., \& Sparling, E. (2014). The effectiveness of the Snug Vest on stereotypic behaviors in children diagnosed with an autism spectrum disorder. Behavior modification, 38(3), 412427.

Wetherby, A. M., \& Woods, J. J. (2006). Early social interaction project for children with autism spectrum disorders beginning in the second year of life: A preliminary study. Topics in Early Childhood Special Education, 26(2), 67-82.

White, S. W., Keonig, K., \& Scahill, L. (2007). Social skills development in children with autism spectrum disorders: A review of the intervention research. Journal of autism and developmental disorders, 37(10), 1858-1868. 
Whitlow, C. K., \& Buggey, T. (2003). Video self-modelling: an effective intervention for a preschooler with language delays. Journal of Research in Special Educational Needs, 3(1), no-no.

Williams, C., Wright, B., Callaghan, G., \& Coughlan, B. (2002). Do children with autism learn to read more readily by computer assisted instruction or traditional book methods? A pilot study. autism, 6(1), 71-91.

Williams, K., MacDermott, S., Ridley, G., Glasson, E. J., \& Wray, J. A. (2008). The prevalence of autism in Australia. Can it be established from existing data? Journal of Paediatrics and Child Health, 44(9), 504-510.

Wilson, A., \& Laskey, N. (2003). Internet based marketing research: a serious alternative to traditional research methods? Marketing Intelligence \& Planning, 21(2), 79-84.

Wing, L., \& Potter, D. (2002). The epidemiology of autistic spectrum disorders: is the prevalence rising? Mental retardation and developmental disabilities research reviews, 8(3), 151-161.

Wise, R. (2014). 15 Behavior Strategies to Help Children with Autism. Retrieved from https://www.linkedin.com/pulse/20140928022649-95218701-15-behavior-strategies-tohelp-children-with-autism/

World Health Organization. (1992). The ICD-10 classification of mental and behavioural disorders: clinical descriptions and diagnostic guidelines (Vol. 1): World Health Organization.

Yoder, P., \& Stone, W. L. (2006). A randomized comparison of the effect of two prelinguistic communication interventions on the acquisition of spoken communication in preschoolers with ASD. Journal of Speech, Language, and Hearing Research, 49(4), 698-711.

Zwaigenbaum, L., Bryson, S., Rogers, T., Roberts, W., Brian, J., \& Szatmari, P. (2005). Behavioral manifestations of autism in the first year of life. International journal of developmental neuroscience, 23(2), 143-152. 